\title{
Interest Rates and Price Level Changes, 1952-69*
}

\author{
by WILLIAM P. YOHE and DENIS S. KARNOSKY
}

Our economy has been experiencing an accelerating inflation during the past five years. At the same time, market interest rates have risen to extremely high levels. The causes of inflation are relatively well-known, but the reasons for high interest rates accompanying inflation are not. The following article investigates primarily this latter situation.

Inflation develops when, at a high level of resource utilization, total spending on final goods and services (GNP) rises at a rate faster than the rate at which productive potential grows. Such has been the case in this country since early 1965. Total spending has risen at an 8 per cent annual rate and real product at a 4.4 per cent rate. As a consequence, the overall price level has risen at a 3.6 per cent annual rate.

The major cause of the current inflation has been the stimulus to total spending provided by an excessive rate of expansion in the money stock. From early 1965 to the end of 1968 , the money stock, on balance, grew at a 5.2 per cent annual rate, compared with a 2 per cent trend rate in the preceding decade.

Rapid grouth in the money stock accompanied by high and rising market interest rates has appeared a paradox to many observers. According to modern Keynesian economic theory, an acceleration in the rate of monetary expansion will provide lower market interest rates. However, this apparent paradox can be explained by the economic theory developed by Irving Fisher around the turn of the century.

According to Fisher, nominal (observed) interest rates consist of two components - the "real" rate of interest, to which real saving and investment respond, and a premium based on expected changes in the price level. The following study uses this Fisherian analysis to quantify the effect of inflation on movements in interest rates from 1952 to 1969 . The principal finding is that past price movements exert a major effect on nominal interest rates, with the effect largely manifested within two years. Consequently, most of the rise in market interest rates since 1965 can be attributed to the current inflation.

This finding has an important implication for market interest rates as an indicator of the thrust of monetary actions on economic activity. High market interest rates do not necessarily indicate monetary restraint. Instead, they most likely indicate excessive monetary ease, (as meastured by rapid expansion of the money supply) which results in rapidly expanding total spending and eventually inflation.

William P. Yohe is currently a visiting scholar with this bank and is also Professor of Economics and Director of Graduate Studies in Economics at Duke University. He is the author of numerous publications, primarily in monetary economics. Denis S. Karnosky is an economist with the Federal Reserve Bank of St. Louis. 
N SUMMARIZING his many years of work on the subject, Irving Fisher cited four empirical relationships between interest rates and price levels: ${ }^{1}$

(1) Interest rates tend to be "high" when prices are rising and "low" when prices are falling.

(2) Interest rate movements lag behind price level changes, which obscures the relationship between them.

(3) There is a marked correlation between interest rates and a weighted average of past price level changes, reflecting effects that are distributed over time.

(4) "High" interest rates accompany "high" prices, and "low" interest rates accompany "low" prices.

The first of these relationships derives from the fact that, if lenders and borrowers could perfectly foresee future price level movements, the former would hedge against changes in the real value of their loan principal by adding the percentage change in prices over the life of the loan to the interest charge; the latter, expecting money income to change in proportion to prices, would readily accept the higher rate.

Fisher attributed the second and third relationships to imperfect foresight about future prices and the resulting inclination to extrapolate past price changes into the future in order to adjust interest rates for expected changes in prices. He devised the concept of the "distributed lag" to explain the way informa" tion about the past affects expectations of the future.

Fisher thought the fourth relationship, frequently called the "Gibson paradox," was an accidental consequence of the other three." What is paradoxical is that the theory prevalent in that period presumably led to the conclusion that interest rates must be low

\footnotetext{
The authors are grateful to Christopher T. Babb and H. A. Margolis for advice on the statistical problems of this study, to Shigeyuki Fukasawa and James B. Greene for making available the results of their unpublished studies, and especially to Keith Carlson, Michael Keran, Thomas Havrilesky, and Edward Kane for helpful suggestions on earlier drafts of this paper.

Irving Fisher, The Theory of Interest (New York: Macmillan, $1930)$, p. 438 . Fisher first discussed these relationships in Appreciation and Interest (New York: Macmillan, 1896), pp. 75 and 76 .

2The term "Gibson paradox" was coined by J. M. Keynes in A T'reatise on Money, Vol. II (London: Macmillan, 1930), pp. 198-208. A. H. Gibson had studied the high correlation between levels of interest rates and prices in England throughout the 19 th and early 20 th centuries. The phenomenon was earlier called the "Ricardo-Tooke conundrum," after the leading antagonists in the Currency SchoolBanking School controversy in England in the first half of the nineteenth century. For a concise exposition of the controversy, see Knut Wicksell, Lectures on Political Economy, Vol. II (London: Routledge and Kegan Paul, 1935), pp. $168-190$.
}

in order to stimulate sufficient investment spending for the price level to be high, while empirically this has not been observed.

The present study is an examination of the second and third of Fisher's propositions, making use of modern data sources and statistical techniques. There is, at present, a major controversy over (1) the advantages and disadvantages of using monetary aggregates as opposed to using interest rates as indicators of the effect of monetary policy actions on the economy, and (2) the adjustments, if any, which must be made to an indicator to "neutralize" it with respect to changes that are not directly the result of policy actions. ${ }^{3}$ Previous studies of the effect of price level changes on interest rates, some of which will be reviewed below, have found the lags to be so long that recent price behavior could be ignored in evaluating changes in observed interest rates. In contrast, results will be presented here based on the 1952-69 period which indicate that the lags are very short, with most of the effect of price level changes on both longand short-term interest rates occurring within two years. Interest rates adjusted to remove the apparent influence of price changes have sometimes moved contrary to movements in observed rates. Furthermore, price changes have had a greater effect on interest rates in the 1960 's than in the 1950 's, and indeed, price changes in the latter period account for nearly all of the movement in interest rates.

\section{Previous Studies of Price Expectations (Fisher) Effects}

Tests for Fisher effects have generally been based on two hypothesized relationships:

$$
\begin{aligned}
& \text { (1) } \mathrm{mat}_{\mathrm{t}}=\dot{\mathrm{P}}_{\mathrm{t}}+\mathrm{rrt}_{\mathrm{t}} \\
& \text { (2) } \dot{p}_{t}=\sum_{i}^{n} w_{i} \dot{P}_{t-i}
\end{aligned}
$$

The first equation states that the nominal interest rate $(r n)$ prevailing at time $t$ for a particular debt instrument is equal to the annual rate of change in prices $(\dot{\boldsymbol{p}})$ expected at time $t$ to occur over the life of the instrument plus its "real" rate of interest $(r r){ }^{4}$

\footnotetext{
3See, for example, Leonall Andersen, Michael Keran, and Emannel Melichar, "The Intuence of Economic Activity on the Money Stock," this Review, August 1969, and Patric $H$. Hendershott, The Nettralized Money Stock (Homewood, nllinois: $\mathrm{R}, \mathrm{D}$. Irwin, 1968).

"Fisher used "real" rate in the sense of "virtual" or "true" rate. Technically, he also induded a third term, $\operatorname{rr}_{t} \hat{P}_{t}^{e}$. on the right side of equation (1). This is the interest that would be earned on the price adjustment to the nominal rate. The term is ordinarily so small that it is customarily
} 
Equation (2) is an application of the theory of "adaptive expectations," "error-learning," or, alternatively, "extrapolative forecasting." Faced with uncertainty about the future, an economic decision-making unit is presumed to base its predictions about future price movements on a weighted average of current and past changes in prices. Thus, in equation (2) the rate of price change expected at time $\left(\dot{P}_{f}^{e}\right)$ for some future period is the weighted sum of actual past price changes $\left(\dot{P}_{t-1}\right)$, where the importance of each past change is reflected in the weight $w_{1}$, and where $n$ indicates how many periods in the past are relevant in forming expectations. "The approach is "adaptive" in the sense that in each period expectations are adjusted (or forecasting errors are corrected) for actual price changes. The approach is "extrapolative" in that past changes are extended (extrapolated) into the future.

Substituting equation (2) into equation (1) yields the form of the equation that is usually estimated:

$$
\text { (3) } r n_{t}=\sum_{i=0}^{\mathbf{n}} w_{i} \dot{P}_{t-i}+r_{t}
$$

The unmeasurable price expectations are not explicitly considered, but instead it is assumed they can be approximated by the observable pattern of past changes in actual prices (or in some other variable that may be critical to the formation of expectations about prices).

Fisher assumed that the weights in equation (3) declined arithmetically as one goes backward in time. His procedure was first to posit a time interval over which the entire effect of price level changes would

omitted For the complete derivation of equation (1), see Appreciation and Interest, pp. 8-11, 66 and 67.

Some studies have also been concemed with the effect of changes in the rate of price change (i.e., price level accelerations) on changes (rather than levels) in interest rates. To see how this may be done, it is necessary to expand $\vec{P}^{\mathrm{a}}$;

$$
\dot{\mathrm{P}} \mathrm{t}=\frac{\mathrm{dP}_{\mathrm{t}}}{\mathrm{P}_{\mathrm{t}}}
$$

Substituting this term in equation (1), differentiating, and manipulating the result yields:

$$
d\left(m_{t}\right)=\left(\frac{d^{2} P_{t}^{t}}{d P_{t}}-\frac{d P_{t}^{e}}{P_{t}}\right) \frac{d P_{t}}{P_{t}}+d\left(r_{t}\right)
$$

The term within the large parentheses represents price acceleration. See, inter alia, Allan H. Meltzer, "The Appropriate Indicators of Monetary Policy, Part I," Savings and Residential Financing: 1969 Conference Proceedings (Chicago: U.S. Savings and Loan League, 1969) p. 14.

"For a concise survey of the theoretical literature on adaptive expectations, see Zvi Griliches, "Distributed Lags: A Survey," Econometrica, January 1967, pp. 42-45. be reflected in a nominal interest rate series, for example, ten years. Ignoring the current period price change, he then computed for each year the weighted average of past price level changes, using a weight of nine for one year earlier, a weight of eight for two years back, and so forth. The weighted price changes divided by the sum of the weights $(9+8+$ $\ldots+0$ ) yielded the weighted average of past rates of price change. Fisher then observed which of these weighted averages best correlated with the nominal interest rate. ${ }^{\text {s }}$ The "best fit" would be obtained where the correlation was highest or where further lengthening of the interval would not add appreciably to the correlation. ${ }^{7}$

A useful statistic for comparing the results of many distributed lag studies is the mean (or average) lag, that is, the time that elapses until half of the effect of a change in the independent variable is reflected in the dependent variable. ${ }^{8}$ Using annual and quarterly data for the United States, Fisher found very long mean lags for the effect of price changes on long- and short-term interest rates. For example, the highest correlation between commercial paper rates and rates of change in the wholesale price index from 1915-27 was obtained when the latter was lagged over 120 quarters ( 30 years), implying a mean lag of about 40 quarters ( 10 years).

6Within the framework of equation (3), Fisher calculated the correlation coefficient corresponding to the following regression equation:

$$
\mathrm{m}_{\mathrm{t}}=\sum_{\mathrm{i}=1}^{\mathrm{n}} \frac{(\mathrm{n}-\mathrm{i})}{\mathrm{n}(\mathrm{n}-\mathrm{i}) / 2} \dot{\mathrm{P}}_{\mathrm{t}-\mathrm{i}}+\mathrm{rr}_{\mathrm{t}}+\mathrm{u}_{\mathrm{t}}
$$

where $n(n-1) / 2$ is the sum of $n$ terms ranging from zero to $(n-1)$.

THis procedure was directly related to the present-day practice of choosing an estinated equation with the highest $R^{2}$ (coefficient of determination or square of the correlation ratio).

The mean lag is simply the weighted-average lag, where the coefficients $\left[w_{i}\right.$ 's in equations (2) and (3)] are used for the weights. When all of the weights are positive, the formula for the mean lag is as follows (Griliches, p. 31):

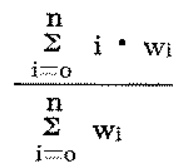

that is a weighted sum divided by the sum of the weights. In Fisher's calculations, the denominator is unity (his weights necessarily sum to one), so the formula for his mean lags is

$$
\sum_{i=1}^{n}\left(i \cdot \frac{n-i}{n(n-1) / 2}\right)
$$

which simplifies to $(\mathrm{n}-1) / 3$. Fisher estimated his mean lags as $\mathrm{n} / \mathrm{3}$. 
In recent years there has been a considerable revival of interest in the study of Fisher effects, ostensibly the result of the reappearance of substantial variability in interest rates and price levels and methodological developments in the estimation of distributed lags. Two studies have attempted to measure "real" rates directly and then to relate the spread between various nominal rates and the estimated "real" rates to historical time series for price level changes, with inconclusive results. ${ }^{9}$

Most of the published studies have regressed nominal rates directly on current and past rates of price changes (or changes in nominal rates on price accelerations). ${ }^{10}$ Data intervals have ranged from quarters (Gibson) to business cycle phases (Friedman and Schwartz). The time span has ranged from as early as 1873 to as late as 1966. Lagged rates of change in various price level indexes and even nominal income (Gibson) have been tried as indicators of price expectations. The forms of the distributed lags estimated have generally been either "uncon" strained" lags or "geometrically decaying" lags." Without exception, the mean lags of interest rates behind price changes were found to be very long. For example, Friedman and Schwartz found mean lags for short-term rates of about ten years and for

${ }^{9}$ Suraj B. Gupta, "Expected Rate of Change in Prices and Rates of Interest" (unpublished dissertation, University of Chicago, 1964), and Phillip Cagan, Determinants and Effects of Changes in the Stock of Money, 1875-1960 (New York: National Bureau of Economic Research, 1965), pp 305-309. Gupta's work is summarized and his empirical work extended in William E. Gibson, "Effects of Money on Interest Rates," Staff Economic Studies, No. 43, Board of Governors of the Federal Reserve System, March 1968, pp. 45-48 and 88-89. Preliminary work along similar lines was reported in David Meiselman, "Bond Yields and the Price Level: The Gibson Paradox Regained," in Deane Carson (ed.), Banking and Monetary Studies (Homewood, Illinois: R. D. Irwir, 1963), pp. 119-122.

10. Meiselman, pp. 112-133; Milton Friedman and Anna Jacobson Schwartz, "Trends in Money, Income, and Prices, 1867 1966" (unpublished manuscript, National Bureau of Ecoconomic Research, November 1966), chapter 2, pp. 110-143; and Gibson, pp. 44,66 and stupplemertary tables. In their multiple regression study, Michael I. Hamburger and William L. Silber ("An Empirical Study of Interest Rate Determination," Review of Economics and Statistics, August 1969 , pp. 369-373) rejected the rate of change in prices as insignificant.

1. Both forms will be disenssed later. To estimate unconstrained lags, one merely regresses the current value of the dependent variable on the current and a predetermined number of lagged values of the independent variable there is thus no a priori constraint on the time shape of the coefficients. Geometrically decaying lags impose a geometrical decay on the coefficients, that is, part of each coeficient is a constant decay term less than one which, when raised to higher powers as the lag recedes into the past decays (asymptotically approaches zero). See Grifiches, pp. 16-49, and Lawrence R. Klein, "The Estimation of Distributed Lags," Econometrica, October 1958 , pp. 553-565. long-term rates of 25 to 30 years, which they attributed to the "slow and gradual adjustment of anticipations of price changes to the actual behavior of prices." 12

\section{A Search for Fisher Effects}

This study is based upon earlier work but departs from previous studies in ways that appear to have significant effects on the results, in particular:

(1) Monthly, instead of exclusively quarterly or annual, data are used for short-term and long-term interest rates (dependent variables) and for price level changes and other independent variables. Further, the interest rate series have been seasonally adjusted.

(2) A variety of kinds of distributed lags are estimated, in order to investigate the effect of lag form on the length of the lags.

(3) The monthly data are aggregated into quarterly and annual series to determine the effect of aggregation over time on the lag estimates.

(4) The study is purposely confined to the period following the Treasury-Federal Reserve Accord of 1951 in order to avoid having to contend with the constraint on interest rate movements imposed by the Federal Reserve's "par pegging" of Government securities prices. Further, the 1952-69 period is divided into two sub-periods to see whether there has been any apparent change in the mechanism relating past price changes to the formation of price expectations and any clues to the reasons for earlier findings of very long lags.

(5) A model will also be tested to see what happens to the explanatory power of past price level changes when variables assumed to affect "real" rates of interest are added to the regressions.

(6) Experimental "real" rate series will be generated and their movements compared with nominal rates to see whether there have been times when nominal rate movements might have been misleading indicators of charges in "real" interest costs.

\section{Seasonal Movements in Interest Rates}

A number of economists have observed not only seasonal movements in monthly and quarterly interest rate series, but also the influence on the seasonal

12Friedman and Schwartz, chapter 2, p. 139. Gupta, estimating geometrically distributed lags for the nominal rate - "real" rate spread behind price changes, found a mean $\mathrm{lag}$ of 16 years for long-tem rates. Gibson estimated unconstrained lags for relatively short lag intervals (ten quarters and four years) so it is not possible to calculate mean lags for the total effect of price changes on interest rates. In Meiselman's study, the geometric decay coefficients came out very close to one, implying a long mean lag (nearly twenty years, for example, with a decay coefficient of 0.967 , which he found in regressing bond yields on price changes over the 1873-1960 period). 
of changes in Federal Reserve operating strategy for open market purchases and sales. ${ }^{13}$ Since some of the data used for independent variables in the regressions were seasonally adjusted, it was advisable to seasonally adjust the short-term and long-term interest rate series, so that the results could be compared with those generated using unadjusted series. ${ }^{14}$ As expected, stronger seasonals were detected in the short-term than in the long-term interest rates. The finding of pronounced seasonals in both for the 195260 period and the virtual elimination of seasonal movements for the 1961-65 period, probably the consequence of the Federal Reserve strategy to assist the balance of payments, confirms the conclusions of earlier studies. The resumption of pronounced seasonals is apparent in the calculations for the 1966 to mid-1969 period. The explanation may lie in the insertion of "proviso clauses" in the Federal Open Market Committee directives over the later period and the implementation of such directives by the Trading Desk at the Federal Reserve Bank of New York. ${ }^{15}$

\section{Empitical Results - Therest Rates Regressed on Rates of Price Change}

Data for the period 1952-69 were used to test the hypotheses about the effect of price expectations on the level of nominal interest rates. Several measures of both prices and interest rates were used in the estimation, and various lengths for the total lags were tested. In addition, several estimation techniques were employed. The results were very similar across the many combinations of data, length of the lag distribution, and estimation procedures, all suggesting a much shorter time horizon in formation of price expectations than had previously been found.

The interest rates used in this study are yields on securities issued by the private sector. ${ }^{16}$ Short-

\footnotetext{
13Leonall C. Andersen, "Seasonal Movements in Financial Variables - Impact of Federal Reserve and Treasury," Business and Government Review, University of Missouri, July-August 1965, pp. 19-26; “A Closer Look at InterestRate Relationships," The Morgan Guaranty Survey, April 1961 , pp. 3-5; Gibsen, pp. $30-32$ and Tables 3 and 4; and Hamburger and Silber, pp. $370-371$.

14Data have been seasonally adjusted using the X-11 Variant of the Census Method II Seasonal Adjustment Program, U. S. Department of Commerce, Bureau of the Census. Source: Board of Governors of the Federal Reserve System, Federal Reserve Bulletin.

15Jan Warren Duggar, "The Proviso Clause and Bank Credit Proxy" (unpublished manuscript, Federal Reserve Bank of New York, 1969).

16Since there are many factors in addition to price expectations that affect the level of interest rates, the dependent variable used in the regressions should be the one least
}

term interest rates $\left(r n^{\S}\right)$ were approximately by the yield on four- to six-month commercial paper. The yield to maturity on Aat-rated corporate bonds was used as the measure of long-term interest rates $\left(r n^{\mathrm{L}}\right)$. Price expectations were approximated by the rate of change of the consumer price index for all items, $\dot{P}^{e}, 17$

Using monthly data for the period January 1952 to September 1969, the function

$$
\mathrm{m}_{\mathrm{t}}=\mathrm{a}_{0}+a_{1} \dot{\mathrm{p}}_{\mathrm{t}}+\mathrm{a}_{2} \dot{\mathrm{p}}_{\mathrm{t}-1}+a_{3} \dot{\mathrm{p}}_{\mathrm{t}-2}+\cdots+
$$

was estimated first by least squares regression of $r n_{t}$ on current and lagged values of price changes for $n=24,36$ and 48 months. The coefficients of the regressions are presented in Chart $I$.

These regressions were run with both seasonally adjusted and nonseasonally adjusted interest rate series, and in each case the results using seasonally adjusted data traced quite closely those using unadjusted data. The introduction of the seasonal factor decreased the unexplained variance (increased the adjusted coefficient of determination, $R^{2}$ ) only slightly. Chart II presents the coefficients of the regressions:

$$
\begin{aligned}
& \mathrm{rm}_{\mathrm{t}}^{\mathrm{s}}=a_{0}+a_{1} \dot{\mathrm{P}}_{\mathrm{t}}+a_{2} \dot{\mathrm{P}}_{\mathrm{t}-1}+\cdots+a_{25} \dot{\mathrm{P}}_{\mathrm{t}-24} \\
& \mathrm{ra}_{\mathrm{t}}^{\mathrm{L}}=a_{0}+a_{1} \dot{\mathrm{P}}_{\mathrm{t}}^{\mathrm{c}_{\mathrm{t}}}+a_{2} \dot{\mathrm{P}}_{\mathrm{t}-\mathrm{t}}+\cdots+a_{25} \dot{\mathrm{P}}_{\mathrm{t}-24}
\end{aligned}
$$

The coefficients using seasonally adjusted interest rates are quite similar to those using unadjusted data.

influenced by those other factors. Yields on private seeurities were selected, instead of rates on Government debt, because they are more free of the direct influences of debtmanagement and monetary actions. However, Fukasawa obtained similar results using yields on Government securities. Greene found that price expectations were somewhat easier to identify using interest rates on private debt.

17 Mortgage costs are included in the consumer price index and might contribute to some degree of spurious correlation between interest rates and price movements. Since mortgage interest rates tend to move with ather nominal rates, using the consumer price index as the measure of price movements would tend to result in a positive bias in the observed relationship between interest rates and price movements. To test for this effect the consumer price index was purged of mortgage rate effects. Data on the mortgage component of the CPI were available from the Bureau of Labor Statistics only for the period 1954-64. Thus, nominal interest rates were regressed on the rate of change of the CPI and the adjusted CPI for this period only. The regressions using this adjusted $\vec{p}^{\circ}$ series were still quite close to those using the index inclusive of mortgage costs. Gibson's procedure of using changes in national income as a proxy for price expectations was also treated, using however, personal income, which is avaitable on a monthly basis. The results, summarized in the appendix, were quite similar to those using the consumer price index. 


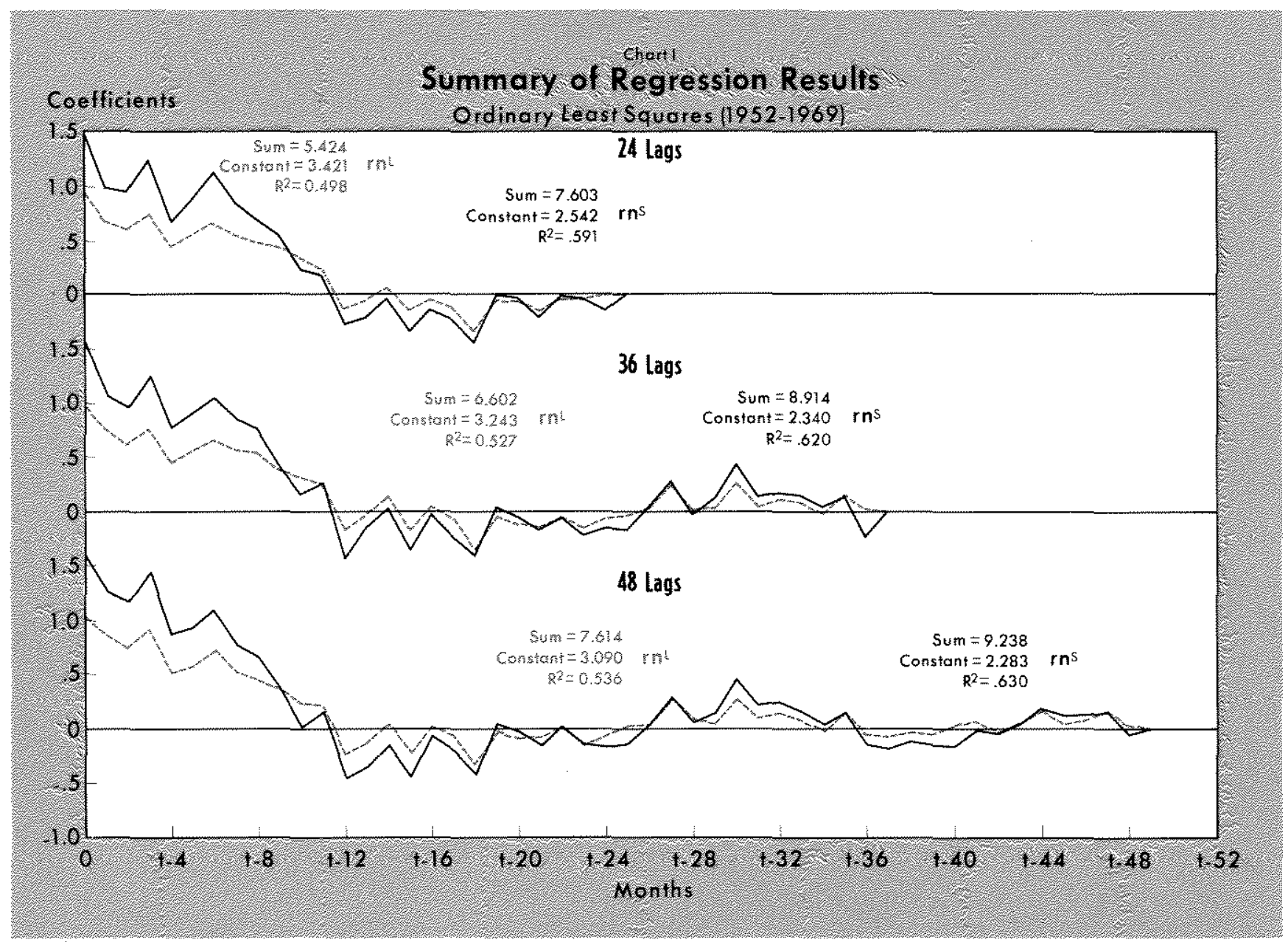

Since this close relationship was observed in all of the tests, only the results using unadjusted data will be explicitly considered.

The regressions show that price movements accounted for about 50 per cent of the variance in interest rates between 1952 and late 1969. The pattern of coefficients is consistent with the adaptive expectations hypothesis, that is, they are generally declining. The presence of small negative coefficients in the "tails" of the distributions could be explained theoretically by the eventual domination of positive "extrapolative effects" by negative "regressive effects" (see page 32 below). Although the t-test is suspect in dealing with a distributed lag regression, ${ }^{18}$ the coefficients tend to be small beyond t-24 months and generally insignificant. Increasing the length of the

\footnotetext{
18Multicollinearity (correlation between independent variables) is a possible source of difficulty in estimation of this type of distributed lag relationship. In the presence of multicollinearity, the ordinary least squares regression technique is inable to identify the exact parameter associated with each independent variable. See I. fohnston, Econometric Methods (New York: McGraw-Hill, 1963), pp. 201-207.
}

lag from 24 to 48 months had little effect on the distribution of coefficients. The sum of the coefficients increased as the lag was extended, however, suggesting that, atthough great weight in the formation of price expectations comes from quite recent experience, the total adjustment procedure is probably somewhat longer, with only relatively small weight given to price movements in the distant past. In other words, the "true" distribution probably has a "tail" of small declining coefficients. These results suggest a much shorter time horizon information of price expectations than had been found in the investigations cited earlier.

Due to multicollinearity, direct estimation of an unconstrained distributed-lag function tends to result in wildly fluctuating coefficients. In order to reduce this fluctuation, the relationships were estimated using the Almon lag technique. ${ }^{19}$ This procedure results in a much smoother distribution, which is more

\footnotetext{
1"Shirley Almon, "The Distributed Lag Between Capital Appropriations and Expenditures," Econometrica, January 1965 , pp. 178-196.
} 


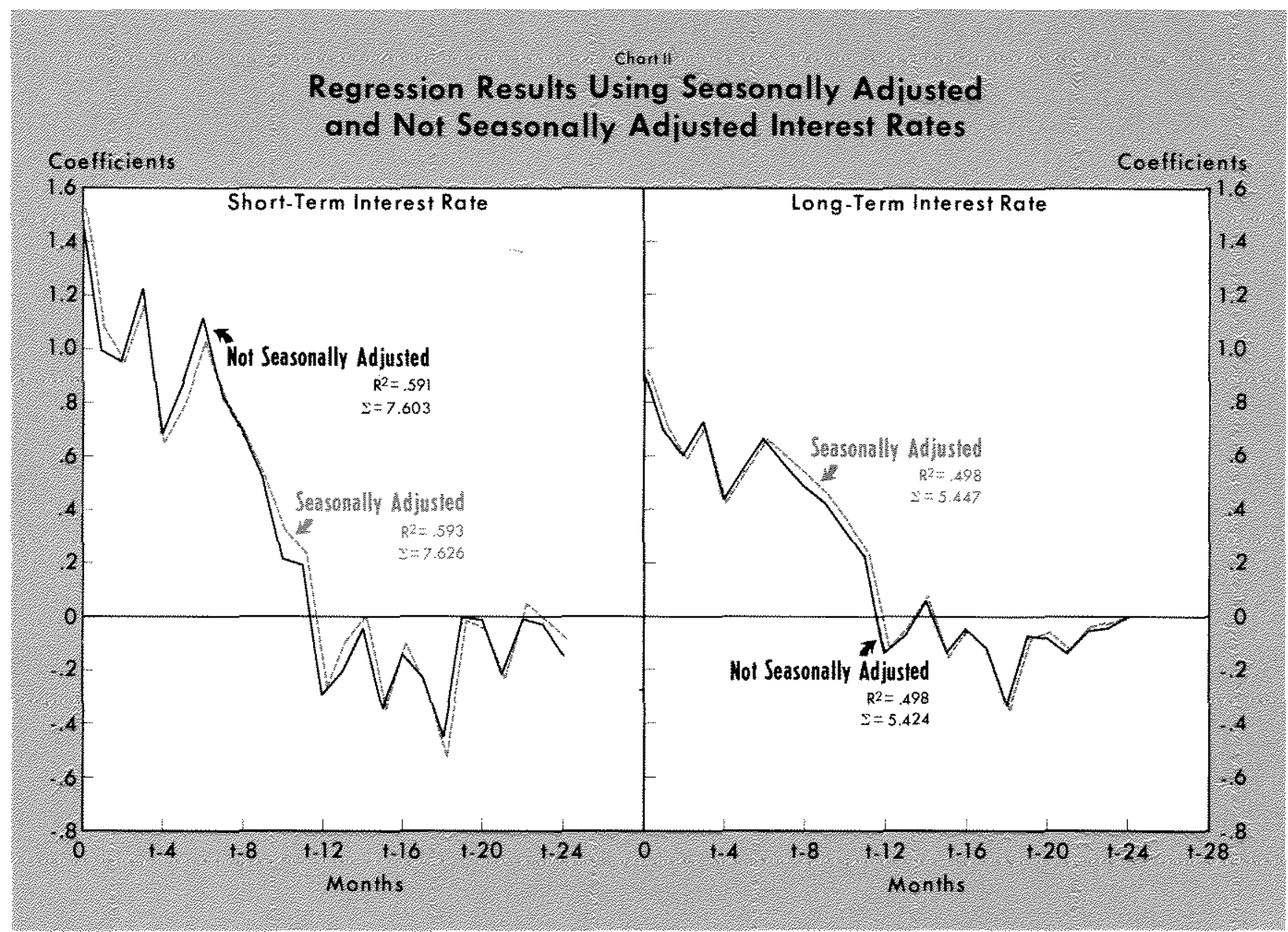

consistent with the adaptive-expectations hypothesis, that is, expectations are a continuous function of past price movements.

The AImon lag estimates are presented in Chart III $^{20}$. The distribution of the Almon coefficients follows the least squares estimate quite closely. For lags from 24 to 48 months, most of the effect on interest rates come from price movements over the previous year. The tails of coefficients beyond these points sum to nearly zero.

The regression using 48 lags suggests that, if the annual rate of change of the consumer price index increased by one per cent in a given month (for

20The regressions presented here were generated using a sixth-degree polynomial, Other degree polynomials were tested and gave similar distributions. The sixth-degree was chosen because it best approximated the unconstrained estimates, in that it minimized the sum of the squares of the difference between the unconstrained and Almon estimates. The only constraint on the selection of the degree of the polynomial is that it must be less than or equal to the number of lagged coefficients. The sixth-degree polynomial was the maximum which condd be used in the prow gram available to the authors. example, from a 3 per cent annual rate of increase to a 4 per cent annual rate) and prices continued to rise at that rate, the yields on four- to six-month commercial paper would rise 72 basis points (for example, from 4 per cent to 4.72 per cent) during the first year, if all other factors affecting interest rates were unchanged. After 48 months, short-term interest rates would have risen by 69 basis points. ${ }^{21}$

21 In the long run, the nominal rate of interest does not rise by the full amount of the change in price expectations. An increase in price expectations will increase the difference between the nominal and Wicksellian market rates. However, the change in price expectations will tend to lower the market rate. Assuming an equilibrium position with expected price changes equal to zero, then rnt=rmi. If price expectations increase by one per cent per year, after 4 years the nominal interest rate will rise by 69 basis points, thus

(1) $\mathrm{m}_{\mathrm{t}}+_{48}-\mathrm{mm}_{\mathrm{t}}+_{48}=1.00$

(2) $\mathrm{m}_{\mathrm{t}}+{ }_{48}-\mathrm{rn}_{\mathrm{t}}=0.69$

Since $\mathrm{m}_{\mathrm{t}}=\mathrm{rm}$, equations (1) and (2) reduce to

(3) $\mathrm{m}_{\mathrm{t}} \mathrm{t}_{48}-\mathrm{mm}_{\mathrm{t}}=-0.31$

Thus the market interest rate falls by 31 basis points following the increase in price expectations. This result is consistent with findings of other investigators; for example, see Keith M, Carlson and Denis S. Kamosky, The Influence 


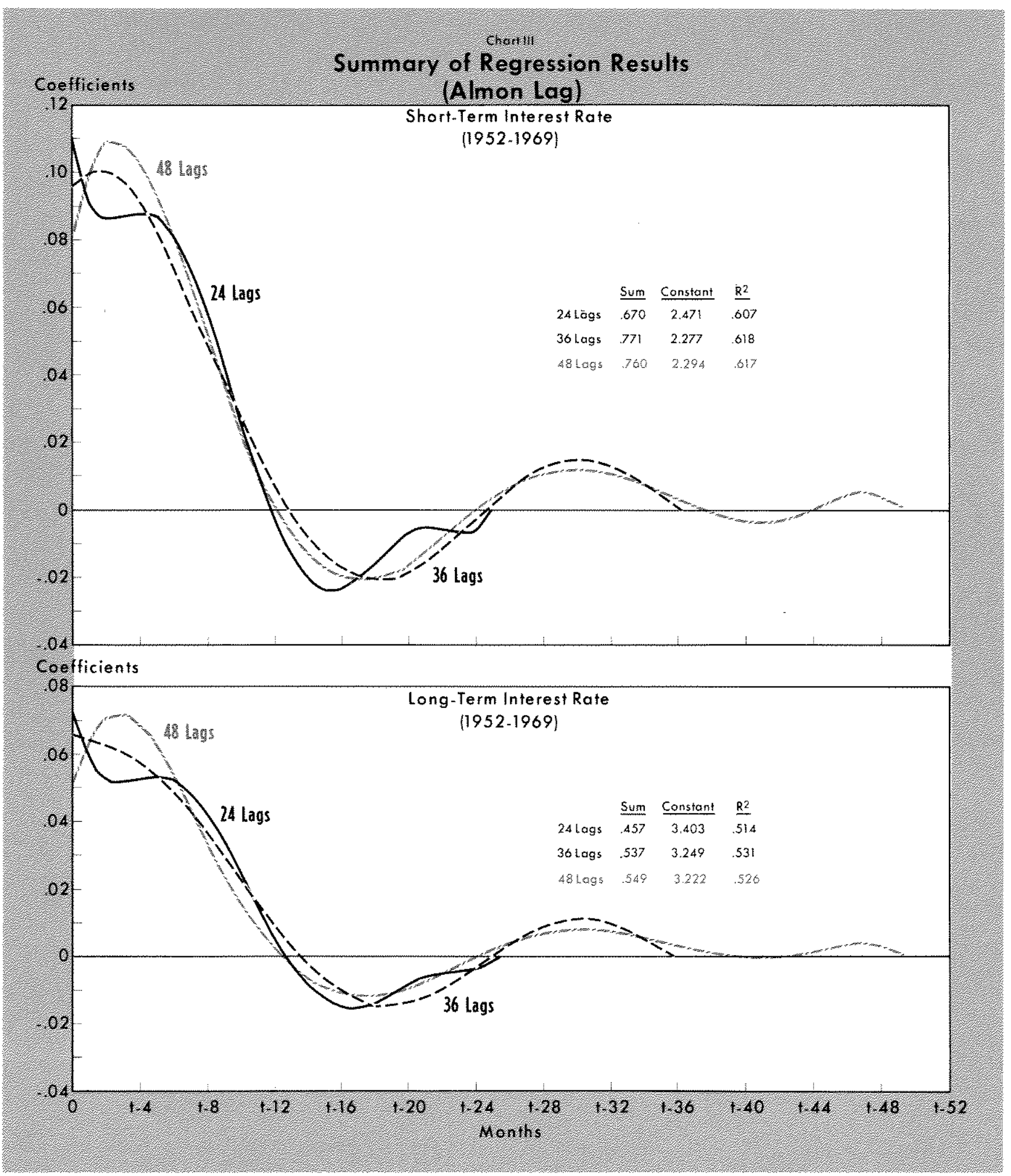

of Fiscal and Monetary Actions on Aggregate Demand: A Quantitative Appraisal, Federal Reserve Bank of St. Louis, Working Paper No. 4, March 1969. In the aggregate demand model developed there, an increase in expected prices ceteris paribus generates a Government budget surplus
Fisher hypothesized that the time horizon in forming price expectations was related to the term to

which results in a decrease in the stock of wealth and reduces the "real" interest rate. The net result is an increase in nominal rates less than the increase in expected prices. 


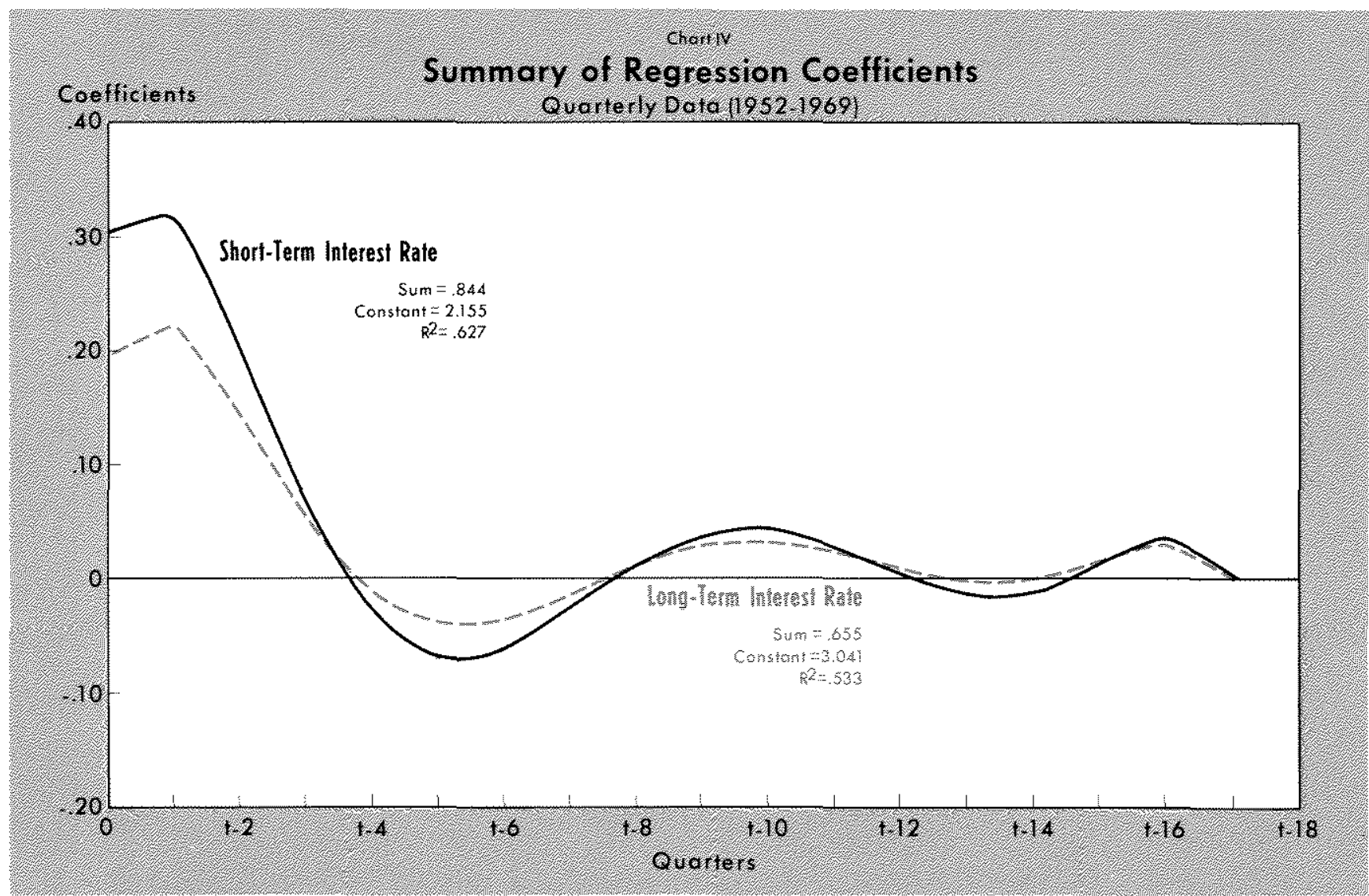

maturity of the instrument. Potential buyers and sellers of long-term debt would be interested in how prices move over an extended period and would tend to look further into the past than would those people who were dealing in short-term instruments. Participants in the market for short-term securities are less likely to be concerned with long-term price movements and might need less information in forming their expectations. The results in the present study are consistent with this idea.

The long-term interest rate is relatively less responsive to changes in price expectations. Twelve months after the one per cent increase in prices, long-term rates would be 59 basis points higher than they were originally, as opposed to 72 basis points for short-term rates. The effect on long-term rates would be a total increase of 56 basis points after 48 months.

\section{Why Such Long Lags In Earlier Studies? - Three Hypotheses}

The present study has found mean lags for the effect of price level changes on both long-term and short-term interest rates of less than a year. In contrast, earlier studies yielded mean lags of anywhere from seven to thirty years. It is important to try to explain this discrepancy and to defend the results presented here.

The authors have explored three hypotheses that might reconcile the differences:

(1) The "true" lags of interest rates behind price changes are short, so that biases arise in aggregating the interest rate and price change series over longer observation periods, which lead to systematic overestimates of the length of the lags. ${ }^{22}$

(2) The forms of the lags estimated in other studies, in contrast to the more flexible class of lags estimated in this study, are biased toward yielding longer average lags.

(3) Institutional changes have occurred over time in financial and real markets, with the result that price level changes have come to have prompter

${ }^{22}$ Griliches, pp. 45-46; Yair Mundlak, "Aggregation Over Time in Distributed Lag Models," Intennational Economic Review, May 1961, pp. 154-163; and Willian R. Bryan, "Bank Adustmonts to Monetary Policy: Alternative Estimates of the Lag," American Economic Review, September 1967, pp. 855-864. Griliches summarizes the issue as follows: "aggregation over time (e.g., from quarterly to annual data will in general result in a misspecification of the model. It will also . . . cause us to overestimate the implied average lags." 


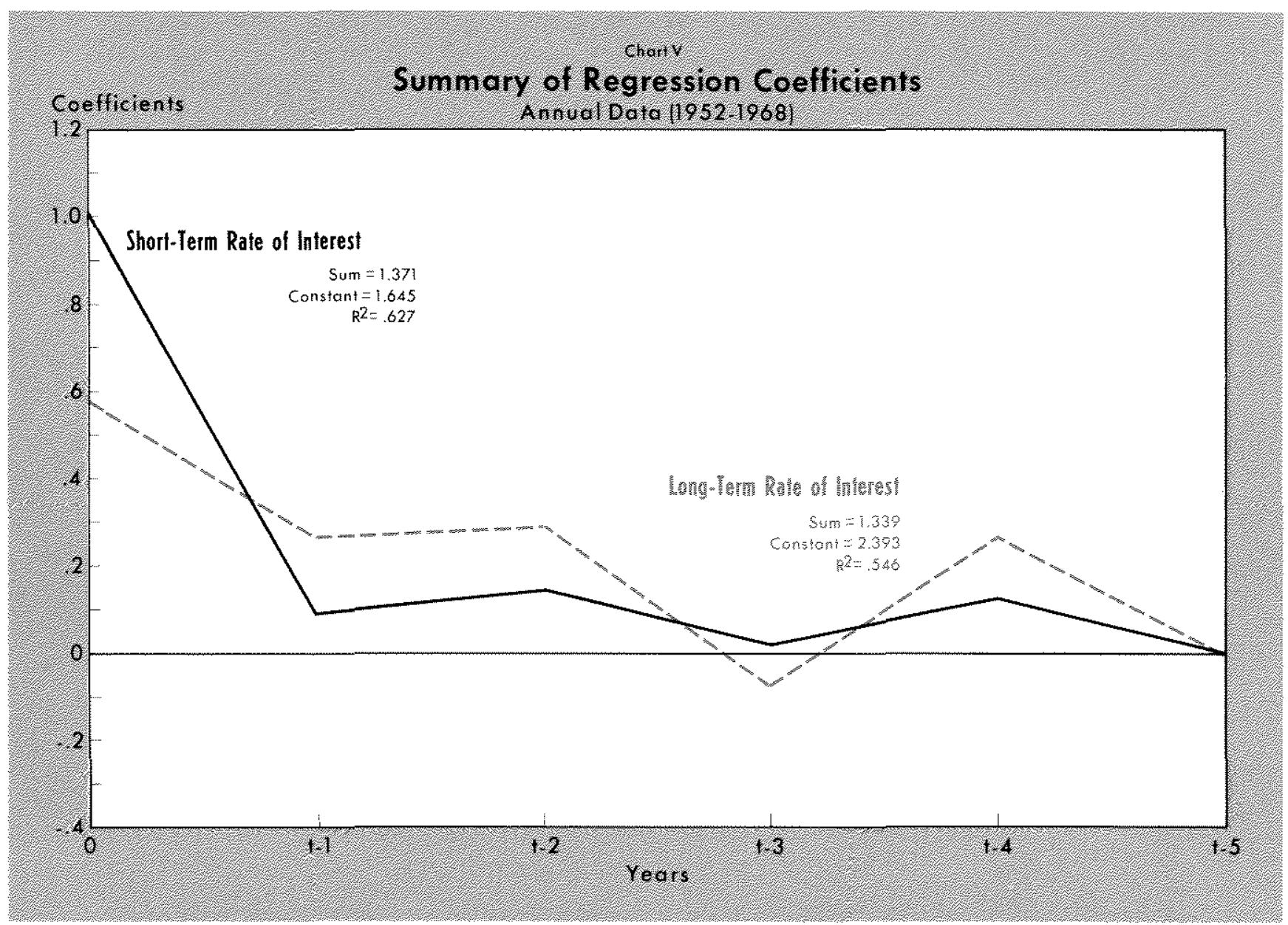

and larger effects on interest rates. ${ }^{23}$ To put it differently, there has been considerable thiming of the "molasses (long-lag) world," particularly in the past decade.

\section{Aggregation of Dana}

To test the first hypothesis, the monthly data for all of the interest rate series and the rate of change in the consumer price index were aggregated to quarterly and annual averages of monthly data for the 1952-69 period. Almon distributed lags over 16 quarters with sixth-degree polynominals were estimated for the quarterly series. The results (see Chart IV) were virtually identical to the original monthly regressions with 48 month lags and the same degree polynomials."2

23"The post-war increase in the degree of financial "market perfection " and its consequent effect on interest rate flexibility is the subject of James $S$. Duesenberry's essay, "The Effect of Policy Instruments on Thrift Institutions," in Savings and Residential Financing: 1969 Conference Proceedings, pp. 135- 143 .

24 Fukasawa has run unconstrained lags extending back six quarters with quarterly data from IV/1951-IV/1968 for Treasury bill and bond rates regressed on the rate of change in the GNP deflator. His resuts are similar to those reported here.
The quarterly regressions suggest that if the annual rate of change of prices increases by one per cent in any quarter and remains at the higher level the shortterm rate would rise by 84 basis points after 4 years. The long-term rate would rise by 66 basis points over the same period. Using the results of the monthly estimates, an increase by one per cent in the annual rate of change in prices, would yield an increase of 69 basis points in short-term rates and 56 basis points in long-term rates after four years.

There were too few observations, given the length of the lags and the degree of the polynomials, to fit Almon lags to the annual observations, so only unconstrained lags were estimated, ranging from one to five years (see Chart V). For the unadjusted commercial paper rate, the $R^{2}$ was highest $(0.709)$ with only the current rate of change in prices in the regres. sion; in all cases, only the coefficient for the current price changes was significant. As might be expected, the $R^{2}$ for the unadjusted corporate Aaa yield was highest (0.552) when the current and one year lagged price change term were included, although in every 
case only the coefficient on the current term was significant. The regressions using annual data gave somewhat larger total effects. If the rate of change of prices rises by one per cent per year, short-term rates would be 137 basis points higher after four years. Long-term rates would rise by 134 basis points.

The discrepancy between this and earlier studies apparently cannot be explained on grounds of an aggregation bias in the latter, and the first hypothesis cannot be accepted. The reason probably lies in the fact that the adjustment of interest rates to price level changes is not so rapid that aggregation of monthly into quarterly and annual data leads to systematic overestimates of the underlying lags.

\section{Estimaton Procedure}

The second hypothesis pertains to the nature of the lag distributions estimated in other studies. Since several of the studies have estimated geometrically decaying (Koyck) lags, the monthly data used in the earlier part of the present study were used to estimate such lags. The following regression was run for each of the yield series, using for $\dot{P}_{\ell}$ both the simple monthly rate of change and compounded annual rates of change: ${ }^{25}$

$$
\mathrm{mn}_{\mathrm{t}}=\lambda \mathrm{ran}_{\mathrm{t} 1}+\beta \dot{\mathrm{P}}_{\mathrm{t}}+\text { constant }
$$

The decay coefficient $\lambda$, presumably somewhere between zero and one, indicates the rate at which the weight of the past rates of price change declines backward in time (that is, $\lambda=1$ means that the lagged terms never decay at all, while $\lambda=0$ means that only the current price change term has any effect).

All of the initial regressions yielded decay coefficients slightly greater than one, which, taken at face value suggests that the lagged terms do not decay.

$$
\begin{array}{ll}
\mathrm{rn}_{\mathrm{t}}^{\mathrm{s}}=1.012 \mathrm{rn}_{\mathrm{t}-1}^{\mathrm{s}}+.057 \dot{\mathrm{P}}_{\mathrm{t}}-.024 & \mathrm{R}^{2}=.980 \\
\mathrm{rn}_{\mathrm{t}}^{\mathrm{L}}=1.007 \mathrm{mn}_{\mathrm{t}-1}^{\mathrm{L}}+.053 \dot{\mathrm{P}}_{\mathrm{t}}-.020 & \mathrm{R}^{2}=.994
\end{array}
$$

A danger in such estimates of the decay coefficients and the $\beta$ parameter is that they are inconsistent, and

25This is the convenient form in which such lags are usually estimated. This equation may be expanded into the following:

$$
\begin{aligned}
& \mathrm{rn}_{\mathrm{t}}=\lambda 0 \beta \dot{\mathrm{P}}_{\mathrm{t}}+\lambda_{1} \beta \dot{\mathrm{P}}_{\mathrm{t}-1}+\lambda^{2} \beta \dot{\mathrm{P}}_{\mathrm{t}-2}+\ldots+\lambda \infty \beta \dot{\mathrm{P}}_{\mathrm{t}-\infty} \\
& + \text { constant }
\end{aligned}
$$

$$
\text { Trat }=\underset{i=0}{\beta \Sigma} \lambda \dot{\mathrm{P}}_{t-i}+\text { constant. }
$$

the estimate of $\lambda$ is probably biased upward. ${ }^{26} \mathrm{Fol}-$ lowing procedures outlined by Griliches and by Goldberger, the decay coefficients were reestimated, which reduced them by only a very small amount:

$$
\begin{aligned}
& \mathrm{m}_{\mathrm{t}}^{\mathrm{s}}=1.005 \mathrm{~m}_{\mathrm{t}-1}^{\mathrm{s}}+.071 \dot{\mathrm{p}}_{\mathrm{t}}-.024 \\
& \mathrm{~m}_{\mathrm{t}}^{\mathrm{L}}=1.003 \mathrm{~m}_{\mathrm{t}-1}^{\mathrm{L}}+.054 \dot{\mathrm{p}}_{\mathrm{t}}-.020
\end{aligned}
$$

Decay coefficients greater than one are clearly inconsistent with the adaptive expectations hypothesis. It would not bo unreasonable to expect decay coefficients only slightly less than one to result from tests using different sample periods or data definitions than were used here.

The monthly data were divided into two subperiods, 1952-60 and 1961-69, and separate estimates of the decay coefficients obtained. For the earlier period, the coefficients dropped below one, ranging (unadjusted for consistency) from 0.977 for commercial paper rates to 0.996 for corporate Aaa yields. These results imply long mean lags for both interest rates, with longer lags for the long-term rates. The coefficients on the current rate of price change in the commercial paper rate regressions strangely became negative for the 1952-60 period. ${ }^{27}$ For 1961-69, the decay coefficients were nearly the same as for the entire $1952-69$ period, that is, slightly greater than one, for which it is difficult to find any theoretical rationalization.

To see what would happen to the decay coefficients, the monthly data were aggregated into quarterly data and the decay coefficients re-estimated for the 1952-69 period and for the subperiods mentioned above. All of the decay coefficients for the entire period declined, which would be expected if a monthly decay process were to be converted into an equivalent quarterly process, but the decay coefficients for shortterm rates fell to below one $(0.968$ for commercial paper rates, with a mean lag of 20 quarters or five years). For $1952-60$ alone, all the coefficients were less than one, but the decay process was again negative for short-term rates. For 1961-69 the results were all plausible, and the decay coefficients were

\footnotetext{
25ee Griliches, p. 41, and Arthur S. Goldberger, Econometric Theory (New York: John Wiley and Sons, 1964), pp. 276-278, and Kenneth $F$. Wallis, "Some Recent Developments in Applied Econometrics: Dynamic Models and Simultaneous Equation Systems," Journal of Economic Literature, September 1969, pp. 774-775.

${ }^{2} 7$ This implies that the lagged price change effects are opposite in sign from those hypothesized; they could be interpreted as evidence for Sargent's "regressive effects" of price changes on short-term rates (sce p. 32 below).
} 
all lower than corresponding coefficients for 1952-60. The effect of price level changes on commercial paper rates for the latter period decayed with a $\lambda$ of 0.834 (mean lag of about three quarters), while the decay factor was 0.919 (mean lag of seven quarters) for corporate Aaa yields. ${ }^{28}$

The preceding experiments with simple geometrically declining lag structures suggest that such lags, requiring an exponential decay, may not be the most appropriate ones to impose on the interest rate and price level data for the period of this study in the attempt to capture the "true" underlying lag distribution. In every case the average lags obtained with this procedure were considerably longer than with either unconstrained or Almon lags, which provides some explanation for the differences between this and previous studies, ${ }^{29}$

\section{Instintiond Changes}

The third hypothesis asserts that price level changes have come to have larger and prompter effects on interest rates because of institutional changes in the economy. As a preliminary test of this hypothesis, the 1952-69 period was again divided into two subperiods, 1952-60 and 1961-69, and various Almon lag structures estimated separately for each, ${ }^{30}$ Table I contains the sum of the lag coefficients for 12 to 48 lags and second- to sixth-degree polynomials.
As was the case with the entire period, there was little difference in the total price expectations effect between different degree polynomials. The length of the lag distribution was crucial, however. The total effect on short-term interest rates tended to decline as the lag was extended beyond 24 months, and this was quite pronounced in the 1961-69 period. The effect on long-term rates, however, increased as the lag was extended up to 36 months. Beyond 36 months, the sum of the coefficients remained almost constant. None of the coefficients beyond 48 months were significant. These results suggest that the time horizon in forming price expectations increases as the term to maturity of the security increases.

The total price expectations effect is much larger in the 1961-69 period than in the earlier period. In the latter period the total effect on short-term rates is about 90 per cent of the annual rate of change in prices. The effect on long-term rates is about 80 per cent of the rate of price change. In the $1952-60$ period the sum of the coefficients range between 5 and 35 per cent of the price change for a lag of 36 months. Chart VI contains the lag coefficients for short-term rates (second-degree polynomial and 24 lags for 1961-69, and sixth-degree with 36 lags for 1952-60) for the relationship between the commercial paper rate and the rate of change in the consumer price

\footnotetext{
28 James B. Greene, using quaterly data for 1961-68, obtained a decay coefficient of 0.824 for the commercial paper rate regressed on the rate of change in the consumer price index, which implies a mean lag of about $21 / 2$ quarters; for the corporate Aaa yield his decay coefficient was 0.919 implying a mean lag of about seven quarters.

2 Experiments were also conducted for the whole period and the subperiods with simple second-order lags (in the regressions the dependent variable was lagged one and two periods ). The results were not appreciably different from those for the first-order lags.

30The "Chow test" was conducted to see whether there was a fundamental shift in behavior patterns within the 1952-1969 period. For both commercial paper rates and corporate Aaa yields the "F" statistics were significant at the one per cent level which indicates a substantial difference in the anticipations forming mechanism in the two subperiods. For an explanation of the test see Gregory C. Chow, "Tests of Equality between Sets of Coefficients in Two Linear Regressions," Econometrica, July 1960 , pp. 591-605.
}

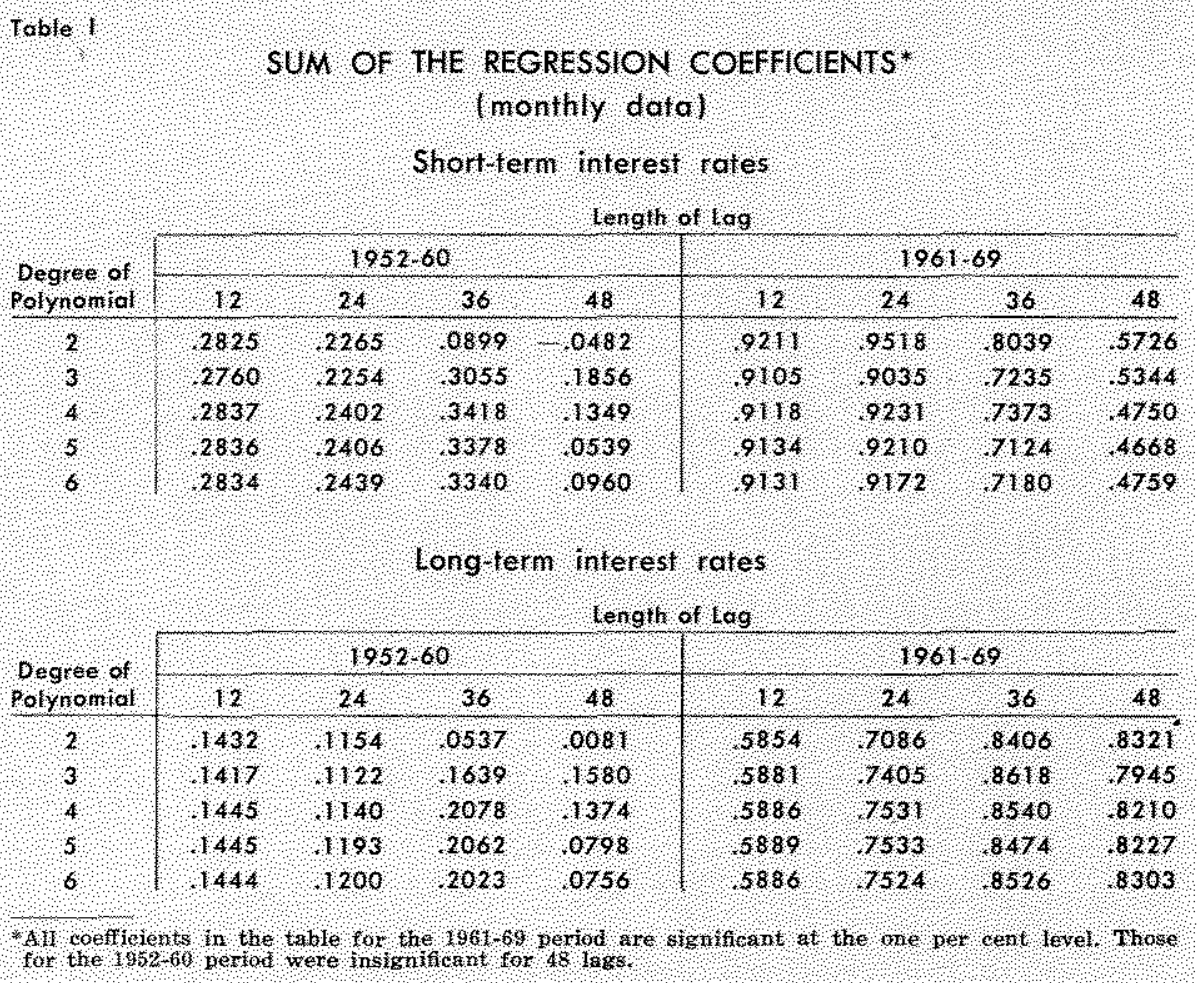




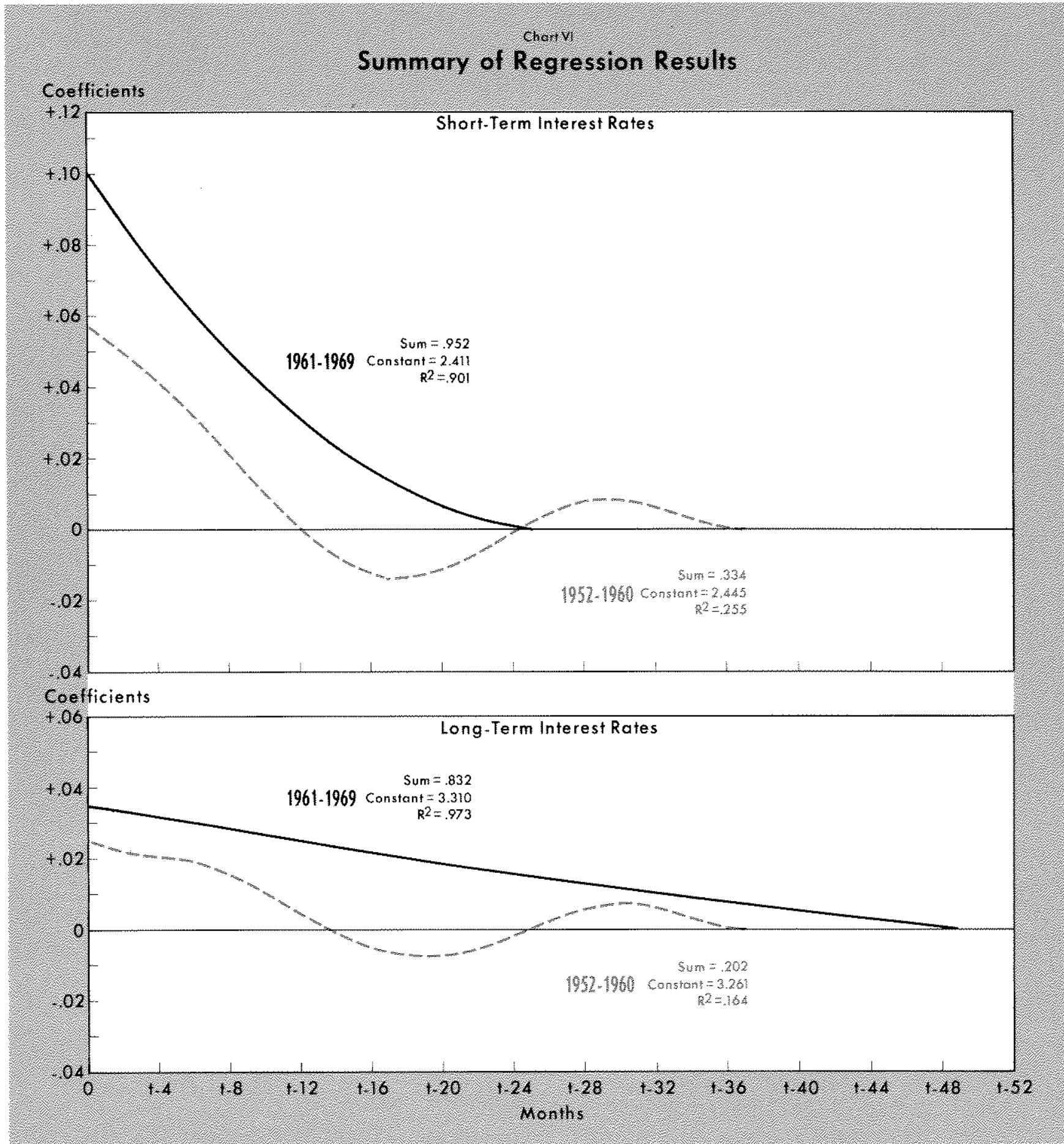

index. The sum of the coefficients for the earlier period was .344 and the mean lag, 1 to 2 months. For the latter period, the sum was .952 , and the mean lag 4 to 5 months. While it is true that the smaller effect in the earlier period was exhausted more quickly (the mean lag was shorter), the peak in total effect for the earlier period was reached after eleven months, while the same level of effect was attained in the latter period in only 2 to 3 months. Further, the $R^{2}$ jumps from 0.255 to 0.901 , so for the latter period the rate of change in prices accounts for over 90 per cent of the variation in commercial paper rates. ${ }^{31}$

\footnotetext{
31 The highest $R^{2}(0.938)$ for the commereial paper rate was obtained for 1961-69 using sixth-degree polynomials and 48 month lags.
} 
These results are thus consistent with the hypothesis of the effect of institutional changes.:3:

Similar results were obtained for the corporate Aat yield (Chart VI), and the jump in $R^{2}$ for the latter period is even more pronounced, from 0.164 to 0.973 . The coefficients of the long-term rate were generated using a second-degree polynomial and 48 lags for 1961-69 and sixth-degree with 36 lags for 1952-60. AII of the coefficients estimated for the 1961-69 period are significant at the one per cent level. A mean lag of 16 months is implied by this result, meaning more than half of the adjustments in interest rates to price changes in the period were attained in less than a year and a half. A summary of the 1961-69 regressions appears in the appendix.

What factors might cause a shift in the framework for transmitting past price level changes, via price expectations, to nominal interest rates? A listing of plausible explanations might include the following:

(1) According to Friedman and Schwartz, "the period used in forming anticipations should depend on the characteristics of price behavior," particularly the "variability in the behavior of the general level of prices." 33 Thus, one could argue that prices have been more variable, at least in an upward direction, in the 1950's and 1960's than over long, earlier histonical periods. Further, the greater publicity given to price level movements, as well as the more rapid processing of data, could convey greater awareness of recent price level behavior and affect price level expectations and interest rates more substantially than once was the case.

(2) Nominal rates may have come to reflect past price level changes more fully both because of a decrease in "money illusion" and because of decreased effects of price changes on real wealth over time.34 The fomer could be explained by the increased importance of large institutional investors in markets such as that for corporate bonds. For the latter to be a contributory factor, real wealth would have to be affected relatively less than before by price changes (because assets not

32 Fukasawa has estimated unconstrained lags with quarterly data for five subperiods from 1951-68 and has obtaned similar results.

33 Friedman and Schwartz, p. 143.

$34^{\text {c }}$ Money illusion" means that behavior is based on and directed toward nomiral magnitudes rather than "real" nagnitudes, for example, investment outlay in money terms would be related to money income and nominal interest rates.

If real wealth infuences the decisions of savers, the saving function would not shift lipward by the expected rate of increase in prices because of expected decreases in the real value of assets fixed in nominal terms (for example, noney), which dampen the effect of price expectations on nominal rates (see Robert Mundell, "Inflation and Real Interest," Jounal of Political Economy, Jutie 1963, pp. $280-283$ ). fixed in nominal terms may have become relatively more important), thus reducing the "drag" on upward shifts in the saving function by the amount of expected price level changes.

(3) Interest rates are more flexible than in many past periods. According to Duesenbery,

"Restrictive monetary policy has in the past operated to a large extent through [nonprice] rationing .... Market forces and public policy have been working toward perfecting capital makkets, and thereby reducing the effectiveness of rationing . . [and resulting in] a world requiring wide swings in interest rates for stabilization purposes ..."35

Thus, one would expect to find larger coefficients linking price changes to interest rates than in the past.

(4) The frame of reference for forming expectations may well have changed, particularly in the $1960^{\prime} \mathrm{s}$. The relative absence of cycles in prices except for the very distant past deprives individuals of a succession of comparable reference points from which to extrapolate into the future and forces the use of heavier weights on the more recent past.

\section{Price Expectations In An Expanded Model}

A recent study by Thomas J. Sargentsi differs from earlier studies of the effect of price expectations on interest rates in two important respects. Besides relating past price changes to nominal interest rates, he sought also to decompose the "real" rate into components representing the equilibrium "real" rate and the deviation of current "real" market rates from the equilibrium rate. In addition, the shapes of the distributed lags he estimated were more general, that is, capable of fitting the data into a greater variety of geometrical configurations.

Sargent devised a useful identity: ${ }^{37}$

$$
\mathrm{m}_{\mathrm{t}}=\underbrace{(\mathrm{a})+(\mathrm{b})}_{\text {"Real" rate }\left(\mathrm{rm}_{\mathrm{t}}=\mathrm{rr}_{\mathrm{t}}\right)}+\underbrace{\left(\mathrm{rm}_{\mathrm{t}}-\mathrm{mm}_{\mathrm{t}}\right)}_{\text {Fisher effect }\left(\dot{\mathrm{P}}_{\mathrm{t}}\right)}
$$

where $r e_{t}$ is the rate of interest at which real saving and investment would be in long-run equilibrium and $r m_{t}$ is the current market level of the "real" rate, that is, $r m_{t}$ is the same as $r r_{t}$ in equation (1) above. Movements in the nominal rate may then be attribm uted to changes in the equilibrium rate (a), to a deviation between the equilibrium rate and the "real" market rate (b), and to a Fisher effect (c).

\footnotetext{
Duesenberry, pp. 136 and 140.

"Thomas J. Sargent, "Commodity Price Expectations and the Interest Rate," Quarterly Journal of Economics, February 1969 , pp. 127-140.

i3Sargent, p. 130. It is an identity, since it simplifies to $m_{\mathrm{t}}=m_{\mathrm{t}}$.
} 
Earlier studies (including that which we have reported above) regarded either (b) or $(a+b)$ as a residual and regressed nominal interest rates on past price changes only, but Sargent attempted to estimate each of the components of the level of nominal rates. The relationships among the components of the nominal rate and how he sought to identify them statistically are shown in Figure $I$. Assume that real investment $(I / P)$ and real saving $(S / P)$ are functions of real income and "real" market rates of interest and that real income is given (so shifts in the saving and investment schedules do not have to be accounted for). The equilibrium "real" interest rate (re) is the rate at which real saving and investment would be in equilibrium. The market rate $(\mathrm{rm})$ below the equilibrium rate indicates that some portion $(A B)$ of current investment is being financed from sources other than intended saving, for example, by newly created money from the banking system or through the drawing down of previously accumulated money balances. This is sometimes called the "Wicksell effect" on interest rates. ${ }^{38}$

Assuming savers and investors form the same price expectations and that neither are subject to "money illusion" (an important Fisherian concept $t^{39}$ ), both functions would be shifted upward by the expected rate of change in prices, $\dot{p}_{\mathrm{t}}=r n_{\mathrm{t}}-r m_{\mathrm{t}}$.

Since the equilibrium rate cannot be directly observed, Sargent used a reduced form proxy for it. He solved his real saving and investment functions simultaneously, so that the one market rate consistent with equilibrium (equality of intended savings and investment) is a function of the other determinants of real saving and investment, namely real income and (from an investment accelerator) the change in real

${ }^{38}$ Knut Wicksell, Lectures on Political Economy, pp. 190-198, and Interest and Prices (London: Macmillan, 1936). Wicksell assumed that savers and investors expected current prices to continue into the future, so he did not need to account for price expectations effects on interest rates. As Sargent points out views similar to Wicksell's were also held by Henry Thornton in 1802 and by Keynes in $A$ Treatise on Money. Emphasis on the equilibrium rate-market rate relationship as the proper one in using interest rates as monetary policy indicators and rejection of price expectations effects on empirical grounds characterizes rew cent work of Patric H. Hendershott and George Horwich (see, for example, "The Appropriate Indicators of Monetary Policy, Part II," in Savings and Residential Financing: 1969 Conference Proceedings, pp. 42-44).

What is here called the "Wicksell effect" may also be interpreted as the "liquidity effect" or "impact effect" of changes in the money stock; similarly, the real GNP variables reflect the "income effect" or "feedback effect" on interest rates associated with changes in the money stock (see references to works by Friedman and Schwartz, Gibson, and Meltzer cited above).

39see footnote 34 above.

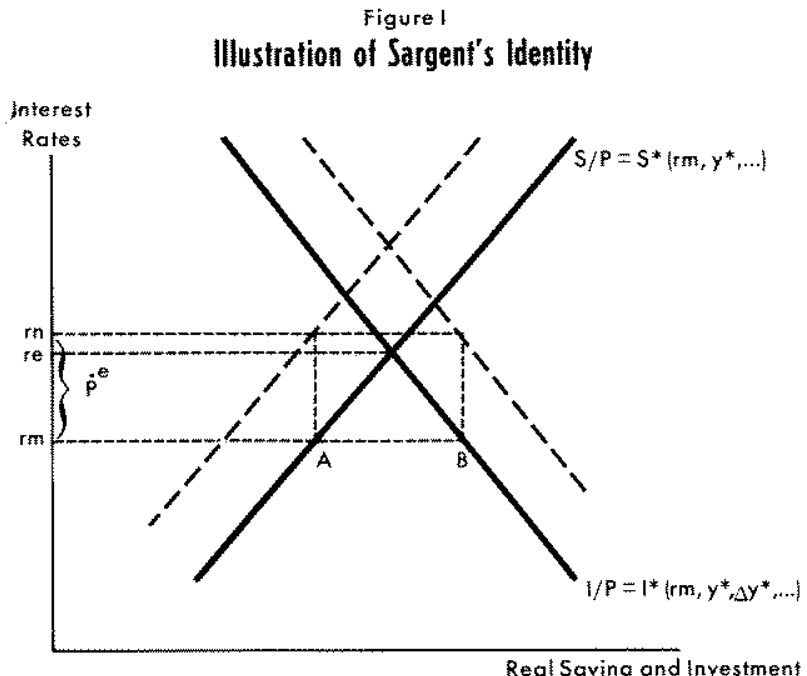

income. This solution was then used to measure component (a) in the equations he estimated. Similarly, having no independent observations for the market rate, he used another proxy, the current rate of change in the "real" (deflated) money stock, for the deviation of the market rate from equilibrium. ${ }^{40}$

Finally, Sargent estimated geometrically distributed lags on past price changes as a proxy for price expectations. Using annual data for 1902-40 (two of the regressions were also run for 1902-54) and taking for nominal rates Durand's one-year and ten-year basic yields, he obtained estimates implying very long mean lags (twenty years or more for short- and long-term rates).

In several of his regressions he estimated two sets of decay coefficients. Both were positive for the longterm rate; for the short-term rate one was negative and more quickly decaying, which Sargent rationalized as indicative of a "regressive effect" of price changes on short-term rates (as opposed to the positive "extrapolative effect"), that is, price changes temporarily generate expectations of changes in the opposite direction (that is, that they will move back to a "normal" level). The sum of the regressive and

40Ir Figure I the gap between the equilibrium and market interest rates will widen as the portion of real investment not financed by current real savings $(A B)$ increases. The rate of change in the real money stock, on the other hand, should be positively correlated with the magnitude of $A B$. As a proxy for (rm-re) the rate of money change should have a negative coefficient (that is, be positively related to an (remrm) gap).

The entire reduced form for "real" rates should also capture the effects of other capital market disturbances, for example, Government surpluses or deficits and the ways they are financed (banking systen versus nonbank public). 
extrapolative weights did not reach a peak until eight years and declined even more slowly thereafter (since the negative component decayed more rapidly), so the mean lag would not be much different from his other results.

The authors have subjected Sargent's basic approach to a further test, with the following modifications:

(1) Both real saving and investment are assumed to depend on both real GNP and "real" market rates of interest. Thus, there is no a priori expectations; as to the sign of the coefficient for the real GNP term in the regressions. A negative coefficient would presumably indicate that shifts in the saving function in response to a change in real GNP outweighed shifts in investment, so that nominal and "real" rates would tend to fall as real GNP rose. ${ }^{41}$ A positive coefficient would suggest just the opposite, while a coefficient near zero might indicate roughly offsetting effects of saving and investment shifts.

(2) Quarterly and monthly instead of annual data are used, and as before, the emphasis is completely on the entire post-accord period and the 1961-1969 subperiod. The regressions with monthly data necessarily use proxies for real GNP (personal income deflated by the consumer price index and, altematively, the index of industrial production) and the GNP price deflator (consumer price index).

(3) The interest rate series and distribited lag forms are different; further, regressions were rum with and without at constant term (Sargent did not suppress the constant term in any of his regressions).

The equations estimated are of the following form:

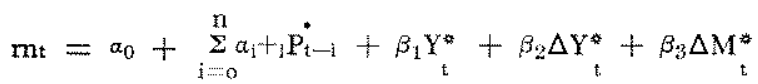

where $\dot{P}$ is the annual rate of change in the GNP deflator (or a monthly proxy), $Y^{*}$ and $\Delta Y^{*}$ are the level and rate of change in real GNP (or a monthly proxy), and $\Delta M^{*}$ is the average change in the real money stock (nominal money stock deflated by the GNP deffator or its monthly proxy). Nominal rates $(r n)$ are again the four- to six-month commerical paper rate $\left(m^{\mathrm{s}}\right)$ and the corporate Aat yield $\left(r n^{\mathrm{L}}\right)$, using quarterly averages of monthly data in the quarterly regressions. Only results for the $1961-69$ subperiod will be reported here, in Chart VII, and in the appendix.

The explanatory power of price level changes was changed little when the equations were more fully

41Sargent obtained negative coefficients in all of his regressions. In his theoretical model lee assumed that only saving was functionally related to the level of real GNP. specified, and the adjusted $R^{2}$ s rose by small amounts. For example in the equations for the long-term rate with second-degree Almon polynomials, total lags of 16 quarters (best statistical fit), and a constant term, the sum of the coefficients on current and lagged rates of price change actually rose from 0.80 to 0.86 , and the $R^{2}$ was unchanged at 0.977 when the current real GNP and real change in the money supply were added to the regression; further, the mean lag for the effect of price changes on nominal rates increased from 3.2 quarters to 5.5 quarters. In other words, recent price changes alone tend to overstate the necessary adjustment of nominal rates to account for the Fisher effect. As would be expected, the coefficients on current and lagged rates of price change were redistributed toward the past in the expanded equations, since the current and last quarters' price levels implicitly enter into the other independent variables. ${ }^{42}$

Suppressing the constant term in the equation (that is, forcing $a_{0}$ to zero) forces a redistribution of its effects over the other coefficients. In the case of the long-term rate, the constant was not significant, and suppressing it enhanced slightly the explanatory power of real GNP and the change in the real money supply, lowered the sum of the price change coefficients (to 0.80) and the acceleration coefficient $\left(\beta_{2}\right)$, left the $R^{2}$ virtually unchanged, and lengthened the mean lag (by three quarters with total lags of 16 quarters). In the case of the short-term rate, the mean lag rose from zero to nearly one quarter. Otherwise, the effects on the coefficients were exactly opposite to what happened when the constant was suppressed in the equation for the long-term rate.

Since the expanded equations contain variables not all measured in the same units, "beta" coefficients were computed in order to assess the relative contribution of each independent variable to the determination of nominal interest rates. In the equation for the long-term rate with various lag lengths the "beta" coefficient for price level changes is nearly three times as large as for real GNP, which ranks second in importance.

42The equation was also estimated for various lengths of total lags without the current rate of price level change (all of Sargent's regressions were of this form) to try to reduce multicollinearity. With total lags of 16 quarters, the sum of the coefficients on the lagged price changes $\left(\sum_{i=0}^{n} a_{i+1}\right)$ rose slightly, $\beta_{1}$ and $\beta_{2}$ remained about the same, $\beta_{3}$ declined in absolute value by about 10 per cent, and the $R^{2}$ and Durbin-Watson statistics rose slightly. 


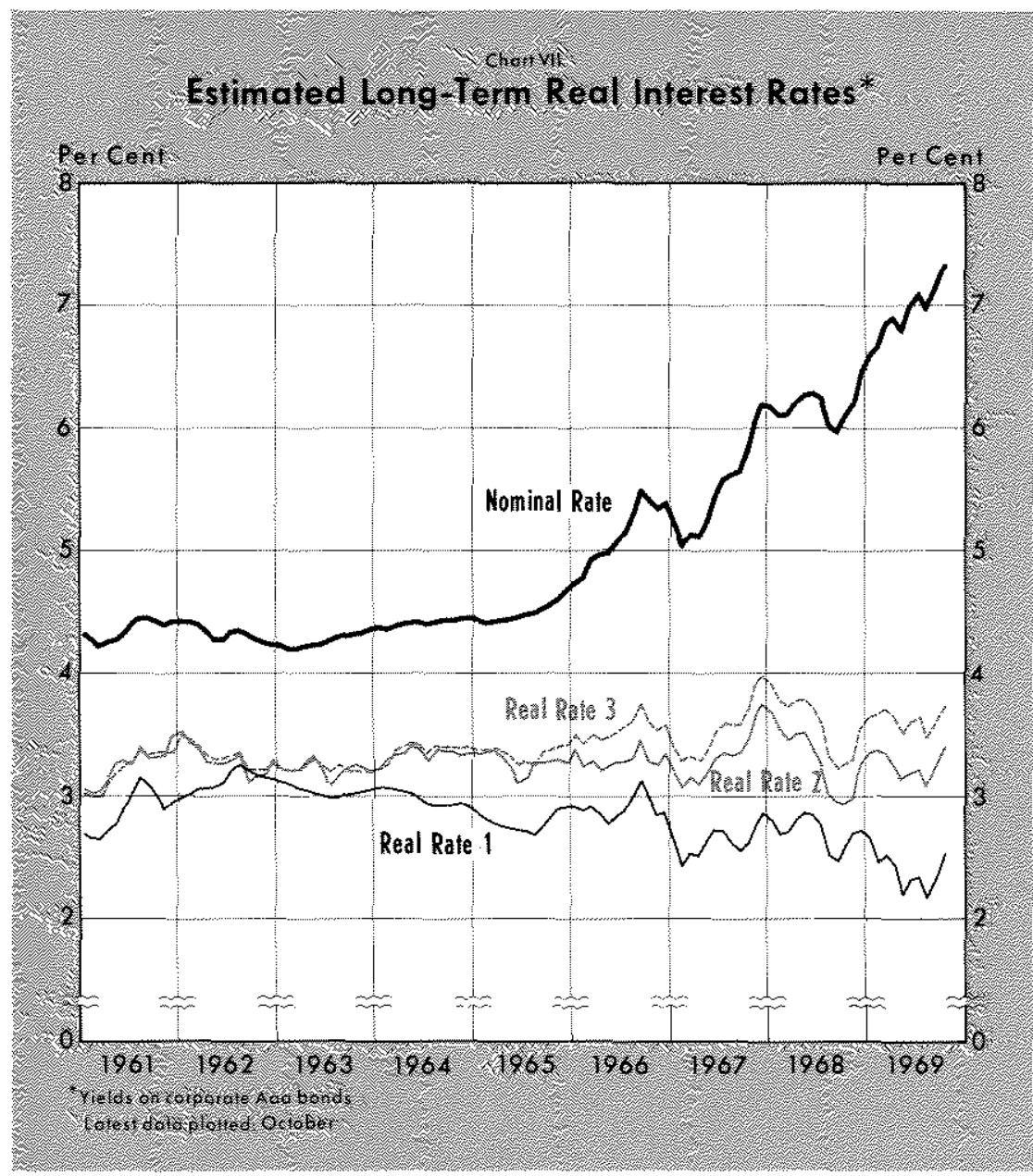

coefficients were smaller than in the quarterly regressions, suggesting that the response of the equilibrium "real" rate of interest to real income growth may occur over a substantially longer period than the current month. ${ }^{44}$

Thus, the findings reported in this section appear to support the specification of variables in Sargent's model. The use of quarterly and monthly data over post-accord period and the estimation of Almon lags provide better statistical results than in his study. The importance of price level changes in explaining nominal interest rates is diluted very little by the expanded equations, and the mean lags are not sufficiently lengthened to alter the con. clusions of the earlier sections of the present study.

\section{Experimental Time Series For The "Real" Rate of Interest}

The Federal Reserve Bank of St. Louis began calculating and publishing an experimental monthly series for the expected "real" rate of return on Cor-

Sargent's expanded model was also tested with monthly data, using alternatively, personal income deflated by the consumer price index and the index of industrial production as proxies for the real GNP (a series derived from the regression using the latter appears in Chart VII as "real" rate 3). The results closely paralleled those for the equations using quarterly data. For example, in the equation for the longterm rate with a total lag of 48 months, the index of industrial production as the real GNP proxy, and a constant term (which was significant in the monthly regressions), the sum of the price change coefficients fell from 0.87 to 0.82 , the mean lag rose slightly from 15.6 to 16.4 months, and the $R^{2}$ went from 0.968 to $0.971 .{ }^{43}$ The change in industrial produotion and the change in the real money supply had the correct signs but were not significant; one month is probably too short a period to capture the full "Wicksell (liquidity) effect." The level of industrial produotion turned out to be quite significant, but the

43Results using personal income deflated by the consumer price index were virtually identical to those using the index of industrial production as the proxy for real GNP. porate Aaa bonds in 1966. ${ }^{45}$ The procedure employed was to subtract from the actual Aaa yield a simple average of rates of change in the implicit GNP price deffator for the previous twelve months (quarterly price deflator data were interpolated to obtain an estimated monthly index). Such a procedure necessarily implies that the mean lag is half as long (six months) as the total lag and that the co-

\footnotetext{
44 It should also be noted that there is another possible source of mis-specification in all of the expanded equations, namely, the interrelationship between changes in the nominal money stock and both price levels and rates of change. In other words, the monetary authorities would be expected to respond to departures from stable prices. One way around this problen is to make the policy variable endogenous in a simultaneously estimated model containing a "reaction function" for the Federal Reserve (see Michael W. Keran and Christopher T. Babb, "An Explanation of Federal Reserve Actions (1933-68), "this Review, July 1969, pp. 7-20, and Raymond G. Torto, "An Endogenous Treatment of the Federal Reserve Systen in a Macro-Econometric Model," unpublished disserfation, Boston College, 1969.

4 "Strong Total Demand, Rising Interest Rates, and Continued Availability of Credit," this Review, August 1966, pp 3 and 4 .
} 
efficients are constrained to sum to one. ${ }^{46}$ Shortly afterward the lag for averaging price changes was extended to 24 months (mean lag of 12 months), and the resulting proxy for the "real" rate has been reported periodically ever since. As a testimonial to the intuition of the series' creator, the distributed lag results in the present study yield estimates of the magnitude of effect and the mean lag which are remarkably close to the original "real" rate series.

Chart VII contains the nominal corporate Aaa yield from 1960 to October 1969 and various estimated monthly "real" rate series. "Real" rate 1 is the original series, that is, the nominal rate minus the average of rates of price change over the preceding two years. "Real" rate 2 is obtained from the regression using monthly data for 1961-69, total lags of 48 months, and second-degree polynomials. "Real" rate 3 is derived from the regression reported in the preceding section, which seeks to explain the contribution of "real" rates, as well as price expectations to nominal rates of interest; "real" rates here are assumed to be related to the level of and changes in the index of industrial production and changes in the deflated money stock.

Detailed analysis of the movements in these series will require a separate study. ${ }^{47}$ Only a few observations will be made here. The pattern of movement in all three "real" rate series is remarkably similar. The old "real" rate 1, however, appears to have overstated the price expectations component of the nominal rate over most of the period. What is of particular interest are the occasions when changes in nominal rates gave apparently false signals about the nature of changes in "real" rates and the extent of agreement about directions of movement among the three "real" rate series.

All three "real" rates indicated that credit conditions were progressively tighter during the first half of 1961 , when the nominal rate was virtually unchanged. The nominal rate was a reasonably good proxy for "real" rates 2 and 3 during 1962 but not for "real" rate 1 , which rose for most of the year (the consequence of heavier implicit weights than the other two series on price changes two years

\footnotetext{
46Mathenatically, $\dot{\mathrm{P}}_{\mathrm{t}}^{\mathrm{c}}={ }_{\mathrm{i}=1}^{\mathrm{N}} \frac{1}{n} \dot{\mathrm{P}}_{\mathrm{t}-\mathrm{i},}$ where $n$ is the length

of the total lag, and there are exactly $n$ coefficients, each of which equals $1 / n$ (hence, the sum is $n-1 / n=1$ ). Moving averages with equal weiglats are discussed by Griliches, p. 25.

"A variety of other monthly and quarterly "real" rate series have been computed, including short-term "real" rates.
}

earlier and lighter weights on the past year). The gradual upward creep in prices from 1963-65 caused "real" rate 1 to creep smoothly downward, generally opposite in direction to the nominal rate. With the different pattern of weights, movements in the "real" rates 2 and 3 were more pronounced, indicating that underlying price level changes were not entirely smooth over the interval.

"Real" rates 1 and 2 fell and "real" rate 3 oscillated around a constant level during the first half of 1966, while the nominal rate rose. From late 1966 until early 1967, all rates moved down in step. From 1967-69, the original "real" rate 1 tended to drift downward and oscillate somewhat ambiguously, although the three "real" rate series fell before nominal rates declined in the summer of 1968.

"Real" rates 2 and 3 moved upward with the nominal rate from late 1968 until early 1969. For several months thereafter, nominal rates did not rise by enough to offset the effects of rapid inflation, with the consequence that the monthly "real" rates actually fell from about February until late in the summer. Such movement in "real" rates could be used to explain, in part, the strength of the 1969 surge in investment spending.

\section{Conclusions}

Citing the findings by Gibson and Sargent of long lags in the forming of price expectations, Hendershott and Horwich recently argmed:

. Their experience contradicts the monetary
voices in govermment, industry and the acad-
emy that proclaim, but do not demonstrate, that
price level expectations, rather than real forces
are largely responsible for interest rate move-
ments in this decade. ${ }^{8}$

In contrast, the present study has shown that, unlike the earlier historical periods on which most of the previous studies have been based, price level changes since 1952 have evidently come to have a prompt and substantial effect on price expectations and nominal interest rates. In addition, the total effect of price expectations on interest rates and the speed at which they are formed appear to have increased greatly since 1960 . This conclusion is invariant to the form or the term of the flexible classes of distributed

\footnotetext{
4"Hendershott and Horwich, "Appropriate Indicator," p 44. Criticizing the earlier "St. Louis "real" rate," they continue, "The Fisherian zeal of that institution would shock no one more than Irving Fisher, who himself stressed the fantastically long lags in the formation of price level expectations and their impact on interest rates in this country."
} 
lags estimated. Most significant is the finding that price level changes, rather than "real" rates, account for nearly all the variation in nominal interest rates since 1961. Furthermore, the addition of variables to the regressions to account explicitly for the "real" rate components of nominal rates does not appreciably alter these findings.

The causes of price level changes over the period of the study have not been investigated. The primary concern has been to determine the extent to which nominal rate movements may be attributed to expectations about future rates of change in prices, so that nominal rates may consequently be adjusted to yield information about movements in underlying "real" rates. ${ }^{49}$ The failure to make such an adjustment and the sole use of changes in nominal rates as indicators of monetary ease or tightness may on occasion give misleading information about the direc-

${ }^{40} \mathrm{An}$ interesting attempt to "neutralize" interest rates with respect to the impact of movements toward or away from full employment was reported in Denuis $R$. Starleaf and James A. Stephenson, "A Suggested Solution to the Monetary Policy Indticator Problem: The Monetary Full Employment Interest Rate," Journal of Finance, September 1969 , pp. 623-641. Unfortmately, the anthors did not incorporate price level changes into their analysis, which is a serious deficiency in their work. tion and the extent of movements in "real" rates. The importance of the Fisher effect to the controversy over appropriate monetary policy indicators has been succinctly stated by David Fand:

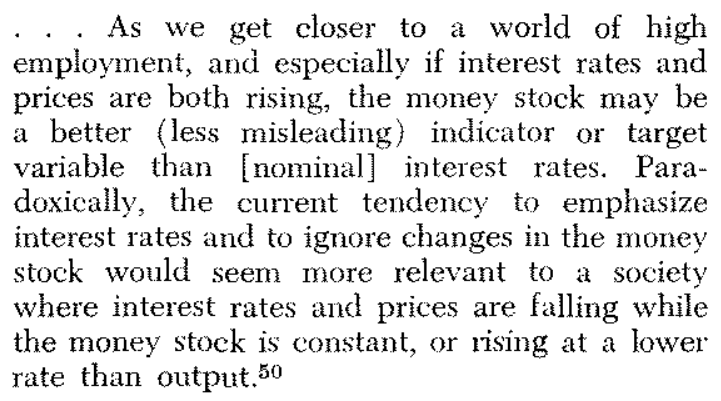
prices are both rising, the money stock may be a better (less misleading) indicator or target variable than [nominal] interest rates. Paradoxically, the current tendency to emphasize interest rates and to ignore changes in the money stock would seem more relevant to a society where interest rates and prices are falling while the money stock is constant, or rising at a lower rate than output. 50

According to economic theory, changes in "real" rates should then reflect both shifts in the equilibrium relationship between real saving and investment and current capital market disequilibrium. Further, it is such "real" rate series that should be employed in studies of the term structure of interest rates and of the effects of international interest rate differentials on short- and long-term capital flows.
5oDavid Fand, "Keynesian Monetary Theories, Stabilization Policy, and the Recent Inflation," Joumal of Money, Credit and Banking, August 1969 , p. 576.

This article is available as Reprint No. 49 .

The Appendix to this article begins on the next page. 


\section{APPENDIX}

\section{Nominal Income As a Prow for Proes}

Gibson suggested that movements in nominal income might serve as a measure of price behavior. His reasoning was that the CPI might be mable to accurately measure short-term price movements since it is a selective index of prices. Nominal income, on the other hand, contains an implicit general price index.

Regressions using carrent and lagged monthly rates of change of nominal personal income $(\dot{\mathrm{P}} \mathrm{y})$ were run and the patterns of coefficients are similar to those resulting from the ruts using the CPI. To adjust for the difference in magnitude between the income and price index series, "beta coefficients" were computed in Table 1 below. ${ }^{1}$

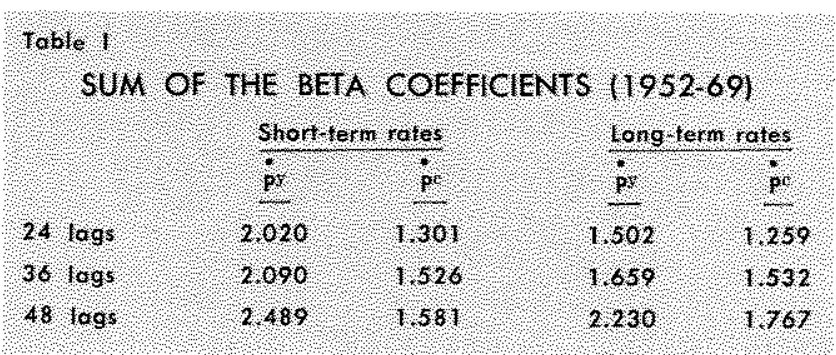

The expectational effects of prices on interest rates, as indicated by movements in nominal income, are larger than those suggested by movements in the CPI. In addition, use of nominal income results in somewhat longer lags, but almost all of the effect still occurs within two years.

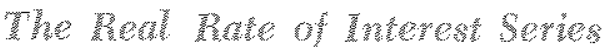

The "real" interest rates (series 2 and 3) presented in Chart VII are actually the Wicksellian "market" rate $\mathbf{I}_{2}$
(mimt) or the long-run equilibrium interest rate plus

1.Arthur S. Goldberger, Econometric Theory (New York: John Wiley \& Sons, 1964), pp. 197-198. any deviations due to short-rur changes in financial markets. The series 2 was generated from the following relationship;

(1) $\quad \stackrel{\mathrm{L}}{\mathrm{mt}}=a_{0}+a_{1} \dot{\mathrm{P}}_{\mathrm{t}}+a_{2} \dot{\mathrm{P}}_{\mathrm{c}-1}+\ldots+a_{49} \dot{\mathrm{P}}_{\mathrm{t}-48}$

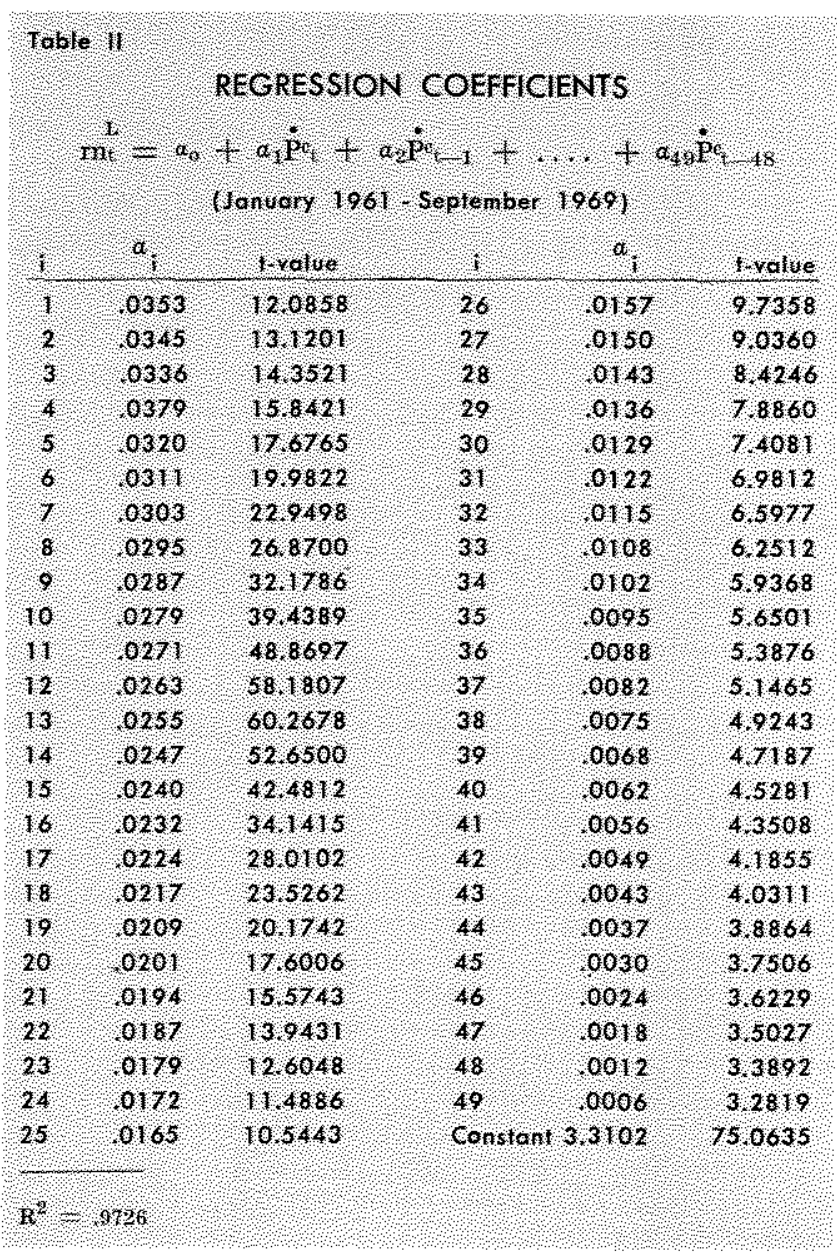




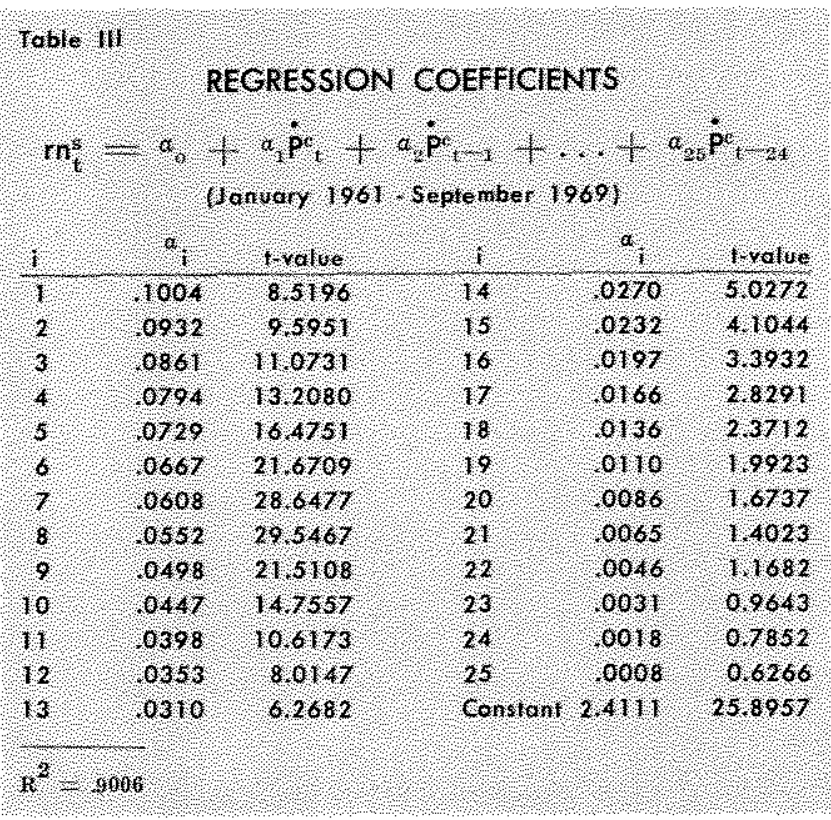

which was estimated by the Almon lag technique, using data for the period January 1961 to September 1969. The series presented is the difference between the actual Aaa yield in each month and the cumulated effect of past prices, or

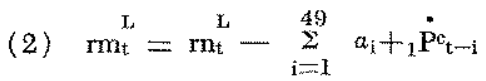

The $a_{i}$ are the estimated coefficients in equation (1) above and $\mathrm{P}_{\mathrm{t}}$ is the annual rate of change of the consumer price index:

$$
\text { (3) } \quad \dot{\mathrm{P}}_{\mathrm{t}}=\left(\frac{\mathrm{CPI}_{\mathrm{t}}}{\mathrm{CPI}_{\mathrm{t}-1}}\right)^{1.2}-1
$$

Notice that the constant $\left(a_{0}\right)$ in equation 1 does not appear in equation 2 . The estimated coeficients $a_{i}$ are presented in Table II. Estimated coefficients for the short-term interest rate are presented in Table III.

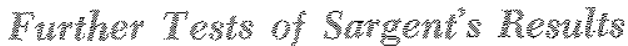

The regressions presented so far attempted to measure the effect of price expectations by regressing nominal interest rates on current and past prices only. Thus the effects of all other factors affecting nominal rates were averaged into the constant term. This approach carries with it the danger of misinterpretation, if the excluded factors affect both the dependent and included independent variables. To test for this possibility, Sargent's approach of explicitly considering some of these other factors was applied.
Using Sargent's model, real output $\left(Y^{*}\right)$, the change in real output $\left(\Delta Y^{\circ}\right)$, and the change in real balances $\left(\Delta M^{*}\right)$ were added to the function, and the following was estimated:

$$
\mathrm{rn}_{\mathrm{i}}=\beta_{\mathrm{t}} \mathrm{Y}_{\mathrm{t}}^{*}+\beta_{2} \Delta \mathrm{Y}_{\mathrm{t}}^{*}+\beta_{3} \Delta M_{\mathrm{t}}^{*}+\sum_{i=0}^{\mathrm{n}} \mathrm{a}_{\mathrm{i}}+\dot{\mathrm{P}}_{\mathrm{t}-\mathrm{i}}
$$

The first two terms on the right determine the equilibriam interest rate $(r e t)$. The real-balances term yields the deviation of real market rates from equilibrium, and the last term captures the price expectation effect.

Quarterly data were used, and real GNP served to measure real output. The annual rate of change of the GNP deflator was used to measure price movements and also to deflate the quarterly changes in the stock of money. Table IV compares these results with the earlier regressions which included only prices as arguments.

The first set of regressions in Table IV apparently has not overstated the total effect of price movements on long-term interest rates, as the sums of the $\alpha_{i}$ co efficients are unchanged in the more completely speci. fied functions. Current and most recent price changes apparently captured some of the effect of contemporaneous output and changes in real balances, however, since the mean lag is more than twice as long in the second set of regressions.

There appears to be some merit in the more extensive specifications. However, inclusion of the additional variables did not drastically alter the conclusions of the original regressions. The mean lag, while longer, is still much shorter than other studies have found. In addition, the real market rates implied by each set of regressions are very similar and suggest that price expectations account for a great deal of the movement in nominal rates since 1961 .

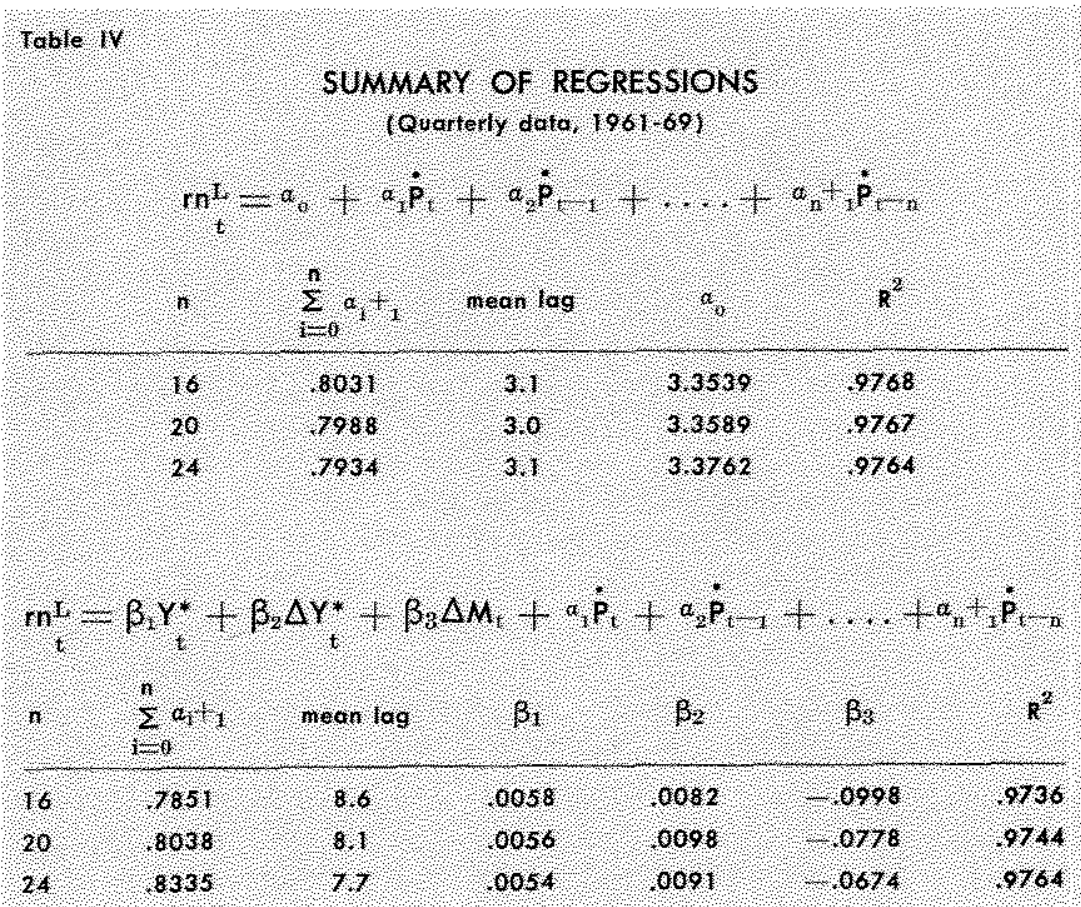

